\title{
Photomechanical Movements of Cultured Embryonic Photoreceptors: Regulation by Exogenous Neuromodulators and by a Regulable Source of Endogenous Dopamine
}

\author{
Deborah L. Stenkamp, ${ }^{1}$ P. Michael luvone, ${ }^{3}$ and Ruben Adler ${ }^{1,2}$ \\ Departments of 'Neuroscience and ${ }^{2}$ Ophthalmology, Johns Hopkins University School of Medicine, Baltimore, Maryland \\ 21287 and ${ }^{3}$ Department of Pharmacology, Emory University School of Medicine, Atlanta, Georgia 30392
}

In the retina of nonmammalian vertebrates, light regulates photoreceptor morphology by causing rod photoreceptor elongation and cone photoreceptor contraction. The opposite photomechanical movements occur in the dark, and proceed with a circadian rhythm in many species in vivo. Using dissociated cultures of embryonic chick retina cells, we have recently demonstrated that photoreceptor cells that differentiate in vitro acquire the capacity of responding to light/ dark cycles with photomechanical movements (Stenkamp and Adler, 1993). Here we report that the putative neuromodulators melatonin and dopamine can mimic the effects of darkness and light, respectively, on in vitro photomechanical movement. Pharmacological studies showed that dopamine appears to function by means of a $D_{2}$-type receptor negatively coupled to adenylate cyclase. The effects of light on the cultured photoreceptors were inhibited by dopamine $D_{2}$ receptor antagonists, and were attenuated by the dopaminergic neurotoxin 6-hydroxydopamine and by the dopamine synthesis inhibitor $\alpha$-methyl-p-tyrosine. The possible existence of an endogenous source of dopamine in the cultures was also suggested by the presence of tyrosine hydroxylase-like immunoreactivity, and of an $\mathrm{Na}^{+}$-dependent mechanism for the accumulation of ${ }^{3} \mathrm{H}$-dopamine, which was predominantly associated with nonphotoreceptor cells. Additionally, ${ }^{3} \mathrm{H}$-dopamine release occurred in vitro through a $\mathrm{Ca}^{2+}$-dependent mechanism, as well as through reverse function of a nomifensine-sensitive dopamine transporter. Both of these putative release mechanisms appeared to be regulated by light and by melatonin, suggesting a mechanism whereby the putative dopaminergic cells may interact with other cells present in the cultures. These studies suggest that complex paracrine neuromodulatory mechanisms can differentiate in low-density embryonic cell culture, that dopaminergic activities exist in vitro, and that they are important for mediating photomechanical movements.

\footnotetext{
Received July 1, 1993; revised Oct. 22, 1993; accepted Nov. 1, 1993.

We are grateful to David Scheurer and Bonnie Johnson for technical assistance, to Harshi Bains and Naomi Barker for help with figures, and to Doris Golembieski for assistance in manuscript preparation. This work was supported by NIH Grants EY-04859 (R.A.) and EY-04864 (P.M.I.), and a National Science Foundation graduate fellowship (D.L.S.).

Correspondence should be addressed to Ruben Adler, M.D., Retinal Degenerations Research Center, The Wilmer Institute, The Johns Hopkins University, School of Medicine, Maumenee 519, 600 North Wolfe Street, Baltimore, MD 21287-9257.

Copyright $(1994$ Society for Neuroscience $0270-6474 / 94 / 143083-14 \$ 05.00 / 0$
}

IKey words: photoreceptor, photomechanical movement, dopamine, melatonin, circadian rhythm, cell culture, dopamine transporter, $D_{2}$ receptor, retina]

The responses of vertebrate retinae to light are not limited to visual transduction. For example, the rates of synthesis of opsin and several other visual proteins and mRNAs vary as a function of an external light cycle, with peak synthesis occurring at the time of light onset (Bowes et al., 1988; Korenbrot and Fernald, 1989). Similarly, a peak of rod photoreceptor outer segment disk shedding and phagocytosis occurs shortly following light onset (reviewed by Bok, 1985). In lower vertebrates, photoreceptor inner segment length is regulated by photomechanical movements, with light initiating rod elongation and cone contraction, and darkncss inducing the oppositc morphological changes (reviewed by Burnside and Dearry, 1986; Kunz, 1990). Some of these cyclic activities persist in the absence of external cues, and are therefore presumed to be circadian in nature (Dearry and Burnside, 1986).

Several neuromodulators are thought to participate in the regulation of retinal responses to light and dark and endogenous circadian clocks (Burnside and Dearry, 1986; Dowling, 1986; Besharse et al., 1988; Cahill and Besharse, 1991). The neuromodulators dopamine and melatonin act as reciprocal antagonists by mimicking the effects of light and darkness, respectively, for many of these rhythmic retinal changes. Their synthesis and release are in turn regulated by the light cycle and, in many cases, by each other (Kramer, 1971; Dubocovich, 1983; Iuvone, 1984; Iuvone et al., 1990). These neuromodulators presumably function in a nonsynaptic fashion, diffusing across the retina from the site of synthesis (Pierce and Besharse, 1985; Besharse et al., 1988; Dearry et al., 1990); these sites are photoreceptor cells for melatonin (Iuvone et al., 1990; Cahill and Besharse, 1993; Weichmann and Craft, 1993), and interplexiform cells or a subpopulation of amacrine cells for dopamine (Dowling and Ehinger, 1978; Dearry and Burnside, 1988).

We have begun to investigate cellular mechanisms for regulation and differentiation of cyclic retinal metabolism using lowdensity cell culture. Chick embryo neural retina precursor cells differentiate as either multipolar neurons or photoreceptors in low-density cultures, where they develop in the absence of retinal pigment epithelium (RPE) and Müller glia. These photoreceptors are anatomically and biochemically polarized, with $\mathrm{Na}^{+}, \mathrm{K}^{+}$-ATPase accumulating in the inner segment and visual pigment immunoreactivity strongest distal to it (Adler, 1986; Madreperla and Adler, 1989; Madreperla et al., 1989). Cultured 
retinal cells also contain serotonin $\mathrm{N}$-acetyltransferase (NAT) activity, which appears to be localized to the photoreceptor cells (Iuvone et al., 1990). We recently showed that these isolated photoreceptors develop and maintain light cycle-dependent activities in the absence of detectable contact with other retinal cell types. When maintained on a $12 \mathrm{hr}$ light/12 hr dark cycle, approximately half of the cultured photoreceptors elongate in response to light, and contract in response to darkness $(\mathrm{L}+)$, with a much smaller subpopulation showing the opposite responses (L-) (Stenkamp and Adler, 1993). The behavior of the more abundant $(\mathrm{L}+)$ subpopulation was chosen as assay to investigate the potential involvement of an intrinsic circadian clock and of various neuromodulator systems in these in vitro responses. The studies suggest that isolated cells establish in vitro a paracrine system of communication that participates in the control of light-regulated, rhythmic photoreceptor behaviors.

\section{Materials and Methods}

Cell culture. Methods for the preparation of the low-density neural retina cultures used in this study have been described (Adler, 1990). Briefly, embryonic day 8 (E8) chick embryo relinas were dissected free of pigment epithelium and other ocular tissues, trypsinized, and mechanically dissociated. The cells were seeded in medium 199 containing $10 \%$ fetal calf serum and $110 \mu \mathrm{g} / \mathrm{ml}$ linoleic acid/serum albumin (GIBCO) on 35 $\mathrm{mm}$ polyornithine-coated dishes at an initial density of $8 \times 10^{5}$ per dish. Cultures were maintained at $37^{\circ} \mathrm{C}$ in a humidified atmosphere of $9 \% \mathrm{O}_{2}, 5 \% \mathrm{CO}_{2}$, and $86 \% \mathrm{~N}_{2}$.

Light/dark treatments. A timed cycle of $12 \mathrm{hr}$ light and $12 \mathrm{hr}$ darkness was in progress throughout the culture period in most experiments. A circular, cool white fluorescent tube, with a neutral density filter, was used to obtain $10 \mathrm{lux}$ intensity at the level of the culture dishes. Constant darkness controls were either covered with aluminum foil, or grown in a separate, light-proof incubator.

Drug treatments. Dopamine, 6-hydroxydopamine (6-OHDA), $\alpha$-methyl-p-tyrosine (AMPT), dibutyryl cAMP (dbcAMP), serotonin, and melatonin were obtained from Sigma, and apomorphine, bromocriptine, SKF-38393, haloperidol, eticlopride, phenylephrine, fluperazine, nomifensine, and 2-iodomelatonin were purchased from Research Biochemicals, Inc. Stock solutions were prepared in Dulbecco's Modified Eagle's Medium (GIBCO) and/or ethanol, and were added to the cultures as indicated in Results, with the appropriate vehicle controls. A red safety light was used when cultures had to be treated during the dark phase of the light cycle.

Photomechanical movements assays. Two complementary assays were used throughout the study for evaluating photoreceptor responses to light (see Stenkamp and Adler, 1993). For both assays, cultures were fixed with $1 \%$ glutaraldehyde in phosphate-buffered saline (PBS), rinsed in buffer, and examined with a Nikon phase-contrast microscope. After quantitation of the total number of photoreceptors and nomphotoreceptor neurons present in the cultures (see Adler and Hatlee, 1989), the number of photoreceptors having an elongated morphology was determined, using as criterion the presence of a constricted inner segment myoid region (diameter of $1.5 \mu \mathrm{m}$; see Fig. $1 B$ and Stenkamp and Adler, 1993). This assay tends to underestimate the magnitude of the response to light: $50 \%$ of the photoreceptors actually increase in length in response to light, but only $20-30 \%$ show the above-mentioned constriction of the inner segment. However, previous studies have shown this characteristic to be a reliable index for assessing the morphological responses of a population of photoreceptors to a light cycle (Stenkamp and Adler, 1993). Ten microscopic fields were counted at $200 \times$ magnification in each culture, representing approximately $1 / 1000$ of the culture area. Counts were done in a "masked" fashion, by an investigator who was not aware of the identity of the cultures. Results are presented as means of triplicate cultures, \pm standard deviation. Experiments were repeated a minimum of three times, with excellent reproducibility. Statistical significance was determined by a one-way analysis of variance, using either a SIDAK test or a Student-Newman-Keuls post hoc test $(\alpha=$ 0.05 ).

A complementary assay involved measuring the length of individual photoreceptor cells between the base of the nuclear compartment (near the origin of the neurite) and the center of the inner segment lipid droplet (Madreperla and Adler, 1989; Stenkamp and Adler, 1993). Fifteen randomly selected photoreceptors were measured in each of three replicate cultures. Results are shown as distribution of photoreceptor lengths for each condition. Although this assay was performed for all experimental conditions to verify the results obtained with the elongated photoreceptor assay, these data are shown only for selected experiments for the sake of brevity.

Western blot analysis of tyrosine hydroxylase-immunoreactive materials. After $6 \mathrm{~d}$ in vitro, (div) retinal cultures were washed once with $\mathrm{Ca}^{2+} / \mathrm{Mg}^{2+}$-free Hank's buffered saline (CMF-HBSS) and harvested in CMF-HBSS containing $0.2 \mathrm{~mm}$ EDTA (CMF-HBSS-EDTA). Ten 35 $\mathrm{mm}$ dishes were pooled for each experimental sample. Cell suspensions were centrifuged at $20,000 \times g$, and the resulting pellet was solubilized in I aemmli sample huffer (Laemmli, 1970). Freshly dissected chicken tissues were frozen in liquid nitrogen, thawed on ice, minced, and homogenized in a glass-glass homogenizer (Wheaton), suspended in CMFHBSS-EDT $\Lambda$, centrifuged, and solubilized as for culture samples. For electrophoresis, $2 \mu \mathrm{g}$ of each sample was loaded per lane on a $10 \%$ polyacrylamide mini gel, electrophoresed, and transferred to a Nytran membrane (Schleicher and Schuell). The membranes were probed with a 1:500 dilution of a rabbit polyclonal antibody against bovine tyrosine hydroxylase (TH) (Eugentech), processed with an alkaline phosphatase detection kit (Vector), and visualized using the "X-Phos" and "NBT" reagents from a DIG riboprobe detection kit (Boehringer-Mannheim). A $1 \mathrm{~mm}$ concentration of levimasole (Sigma) was added during the color reaction to inhibit endogenous phosphatases.

${ }^{3} H$-dopamine accumulation and release. Cultures were washed with $40 \mathrm{~mm}$ Tris-HFPFS, $140 \mathrm{~mm} \mathrm{NaCl}, 5 \mathrm{~mm} \mathrm{KCl}, 1 \mathrm{~mm} \mathrm{MgCl}, 0.1 \mathrm{~mm}$ $\mathrm{CaCl}_{2}, \mathrm{pH} 7.4$ (THM), and incubated in THM containing ${ }^{3} \mathrm{H}$-dopamine (Dupont-New England Nuclear; specific activity, $33.25 \mathrm{Ci} / \mathrm{mmol}$ ) at different concentrations $(0.3 \mu \mathrm{M}$ for most experiments) for $15 \mathrm{~min}$ at $37^{\circ} \mathrm{C}$. In some experiments, $\mathrm{CoCl}_{2}$ was substituted for $\mathrm{CaCl}_{2}\left(\mathrm{Ca}^{2+}\right.$-free THM), while choline chloride was substituted for $\mathrm{NaCl}\left(\mathrm{Na}^{+}\right.$-free $\left.\mathrm{THM}\right)$ in others. The dopamine-transporter inhibitor nomifensine was present at $10 \mu \mathrm{M}$ in the incubation medium in several experiments. Following the incubation period, the cells were washed with THM and solubilized in Opti-Fluor $O$ (Packard) Hluid for determination of cellular radioactivity by liquid scintillation counting, or fixed with $1 \%$ glutaraldehyde in PBS for autoradiography (see below).

Autoradiography. Fixed cultures were washed with PBS, dehydrated with ethanol, and coated with a 50\% dilution of NTB-2 emulsion (Kodak). Cultures were exposed in the dark for $7 \mathrm{~d}$, developed with Amidol developer (Kodak), fixed in 5\% sodium thiosulfate, and mounted with Polymount (Polysciences).

\section{Results}

\section{Description of cultures}

Freshly seeded, low-density chick neural retina cultures appear morphologically homogeneous in composition, but two morphologically identifiable cell types differentiate after 3-6 div (Fig. 1A). Multipolar neurons have large cell bodies and several long neurites. They have been previously characterized by their sensitivity to kainate toxicity, and by the presence of ChAT activity and high-affinity uptake mechanisms for $\mathrm{G} \Lambda \mathrm{B} \Lambda$ and glutamate (Adler, 1990). The photoreceptor cells differentiate somewhat later and can be identified by their polarized morphology, with a single short neurite, a cell body occupied exclusively by the nucleus, an inner segment with a conspicuous lipid droplet, and a distal cilium immunoreactive with visual pigment antibodies (Adler, 1986). These cells show light-sensitive photomechanical movements when maintained on a light cycle, with $50 \%$ of the photoreceptors elongating in response to light and contracting in darkness ( $L+$ subpopulation; Stenkamp and Adler, 1993). A smaller subpopulation contracts in light and elongates in darkness $(\mathrm{L}-$ ), while $30 \%$ of the cells show no changes (Lo cells). Figure 1 illustrates cultures fixed at the end of the dark period (Fig. 1 $A$ ), when short photoreceptors predominate, and at the end of the light period (Fig. $1 B$ ), when elongated cells are most abundant. The figure also illustrates the 

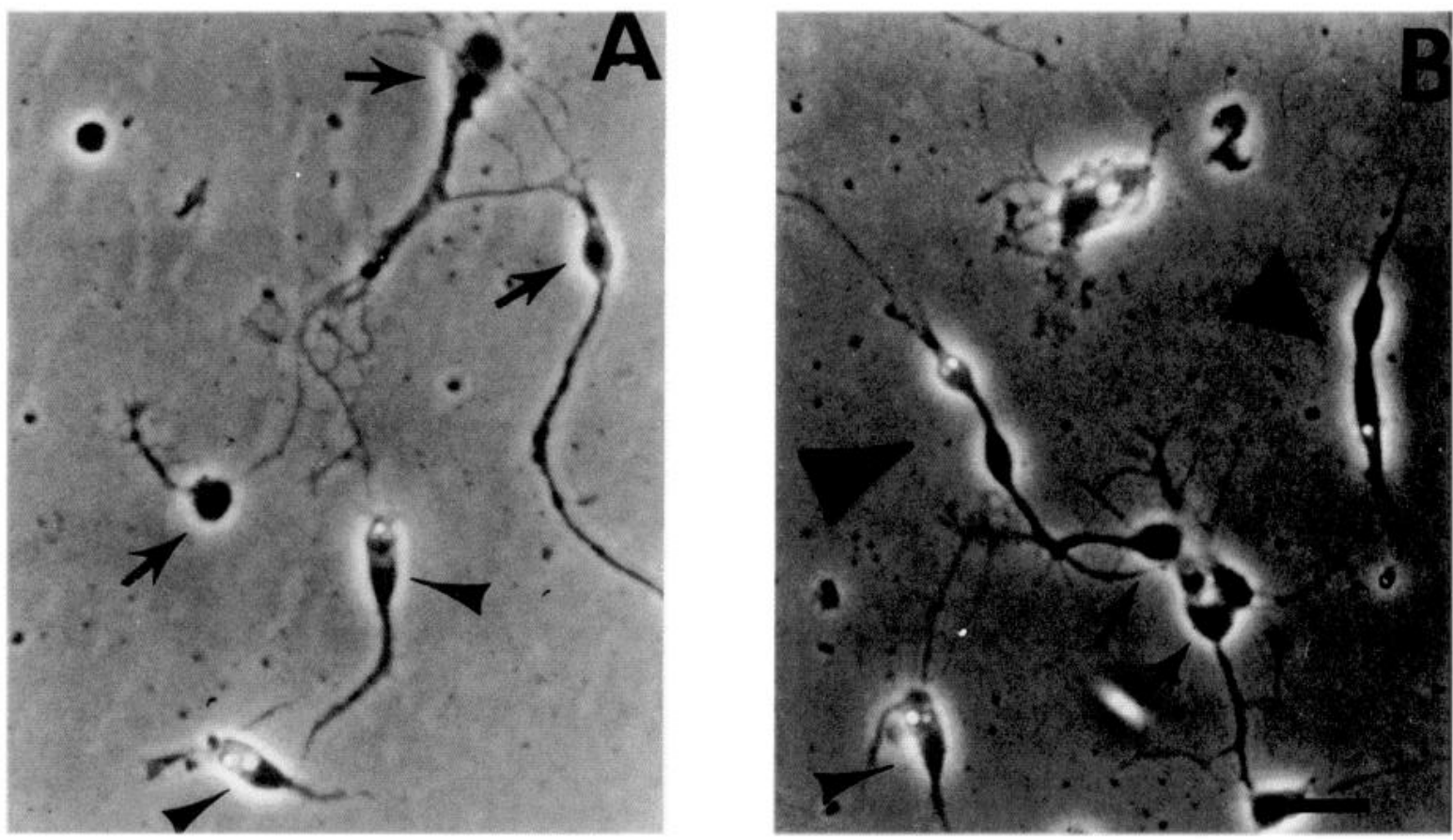

Figure 1. Embryonic chick neural retina cultures fixed at the same time of day (4:00 P.M.) at 6 div. A, Cultures incubated in constant darkness. $B$, Cultures incubated on a 12:12 hr light/dark cycle, fixed for photography during a light period. Arrowheads, photoreceptors; arrows, neurons. Photoreceptors indicated with large arrowheads in $B$ have an "elongated photoreceptor" morphology; the narrow connection between the inner segment and the nuclear compartment is $\langle 1.5 \mu \mathrm{m}$ in diameter (see Materials and Methods and Results). Scale bar, $10 \mu \mathrm{m}$.

constriction observed in the inner segment of many elongated photoreceptors, which was used throughout these studies as a practical criterion for quantitation of the frequency of elongated photoreceptors (see Materials and Methods).

\section{In vitro photomechanical movements can be regulated by melatonin and dopamine}

General design of the experiments. The experimental paradigms used to test the effects of pharmacological agents related to dopamine and melatonin are shown in Figure 2. To test for inhibition of the effects of light, compounds were added in the dark, prior to light onset, and cultures were fixed $6 \mathrm{hr}$ later, during the subsequent light period (Fig. 2A). To investigate possible inhibition of the effects of darkness, compounds were added prior to light offset, and cultures were fixed $6 \mathrm{hr}$ later, during the subsequent dark period (Fig. $2 B$ ). The experiments described in Figure $2 C-D$ were possible because rhythmic photomechanical responses were found not to persist in the absence of a light/dark cycle (data not shown; Stenkamp and Adler, 1993), allowing the testing of compounds for their ability to mimic the effects of light [by acting on cells kept in the dark during a light phase of the cycle ("expected light/actual darkness"); Fig. 2C], or to mimic darkness [by acting on cells kept in the light during an expected dark period ("expected darkness/ actual light"); Fig. 2D]. For experiments illustrated in Figure 2, $C$ and $D$, controls included cultures that were actually exposed to the appropriate "expected" condition, as well as cultures exposed to the "actual" illumination condition.

Effects of melatonin and melatonin agonists. As shown in Figure $3 A$, treatment of the cultures during the light cycle with $1 \mu \mathrm{M}$ melatonin (a dark-adaptive neuromodulator; reviewed by Dubocovich, 1988) or 2-iodomelatonin (a melatonin receptor agonist; Dubocovich and Takehashi, 1987) resulted in a signif- icant decrease in the frequency of elongated photoreceptors as compared to controls. The same reagents also showed the capacity to mimic darkness (Fig. $3 B$ ); serotonin was ineffective at a similar concentration $(1 \mu \mathrm{M})$. Photoreceptor length distributions in expected light/actual light and expected darkness/actual light cultures treated with melatonin or 2-iodomelatonin were strikingly similar to those in dark control cultures (Table 1).
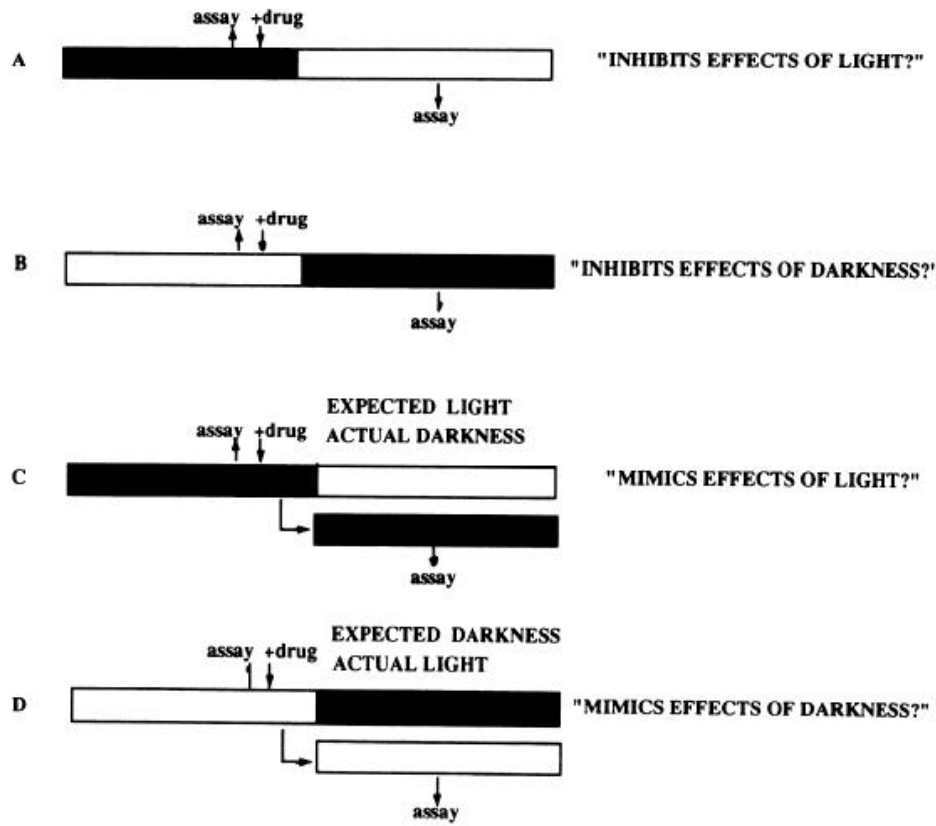

Figure 2. Experimental paradigms used to investigate effects of various drugs on photomechanical movements in vitro. Solid bars indicate a 12 hr dark period; open bars, a light period. Each design asks a specific experimental question, as indicated to the right. 


\begin{tabular}{|c|c|c|c|c|c|c|c|c|}
\hline \multirow{2}{*}{$\begin{array}{l}\text { Exptl. } \\
\text { para- } \\
\text { digm }^{a}\end{array}$} & \multirow[b]{2}{*}{$\begin{array}{l}\text { Expected } \\
\text { condition }\end{array}$} & \multirow[b]{2}{*}{$\begin{array}{l}\text { Actual } \\
\text { condition }\end{array}$} & \multirow[b]{2}{*}{$\begin{array}{l}\text { Melatonin } \\
\text { agonist }\end{array}$} & \multicolumn{5}{|c|}{ Photoreceptor length distribution (\%) } \\
\hline & & & & $\begin{array}{l}10-14 \\
\mu \mathrm{m}\end{array}$ & $\begin{array}{l}15-19 \\
\mu \mathrm{m}\end{array}$ & $\begin{array}{l}20-24 \\
\mu \mathrm{m}\end{array}$ & $\begin{array}{l}25-29 \\
\mu \mathrm{m}\end{array}$ & $\begin{array}{l}>30 \\
\mu \mathrm{m}\end{array}$ \\
\hline \multirow[t]{5}{*}{ A } & Dark $^{b}$ & Dark $^{h}$ & - & 40.0 & 46.7 & 11.1 & 2.2 & 0 \\
\hline & Light & Light & - & 4.4 & 48.9 & 31.1 & 11.1 & 4.4 \\
\hline & Light & Light & Melatonin & 20.0 & 37.8 & 35.6 & 6.7 & 0 \\
\hline & Light & Light & Melatonin ${ }^{d}$ & 44.4 & 46.7 & 6.7 & 2.2 & 0 \\
\hline & Light & Light & I-melatonin ${ }^{d}$ & 33.3 & 37.8 & 28.9 & 0 & 0 \\
\hline \multirow[t]{6}{*}{$\mathrm{D}$} & Light $^{b}$ & Light $^{h}$ & - & 17.8 & 35.6 & 37.8 & 6.7 & 2.2 \\
\hline & Dark & Dark & - & 35.6 & 44.4 & 13.3 & 4.4 & 2.2 \\
\hline & Dark & Light & - & 20.0 & 40.0 & 28.9 & 11.1 & 0 \\
\hline & Dark & Light & Serotonin $^{d}$ & 26.7 & 40.0 & 17.8 & 13.3 & 2.2 \\
\hline & Dark & Light & Melatonin $^{d}$ & 46.7 & 33.3 & 13.3 & 6.7 & 0 \\
\hline & Dark & Light & I-melatonin ${ }^{d}$ & 31.1 & 44.4 & 15.6 & 6.7 & 2.2 \\
\hline
\end{tabular}

Neural retina cultures were examined after a $6 \mathrm{hr}$ treatment with melatonin or melatonin receptor agonist. Forty-five photoreceptors were measured for each condition ( 15 in each of three $35 \mathrm{~mm}$ dishes) and were assigned to $5 \mu \mathrm{m}$ bins based on length. The table shows distributions of these lengths according to illumination condition and drug treatment.

${ }^{a}$ Experimental paradigms as described in Figure 2.

'Assayed prior to addition of drug/vehicle.

' Drug added at $100 \mathrm{~nm}$.

${ }^{\prime}$ Drug added at $1 \mu \mathrm{M}$.

Effects of dopamine and dopamine agonists. Treatment of cultures with dopamine resulted in robust, dose-dependent increases in the frequency of elongated photoreceptors in cultures in expected light/actual darkness (Fig. 4), with $10 \mu \mathrm{M}$ dopamine mimicking and $100 \mu \mathrm{M}$ surpassing the light-stimulated percentages of elongated photoreceptors. Analysis of photoreceptor length distributions corroborated that dopamine exerts lightadaptive effects during expected light (Table 2).

Results with various dopamine agonists using two different assays are summarized in Tables 2 and 3. When added at a concentration of $10 \mu \mathrm{M}$, the $\mathrm{D}_{2}$-like receptor agonist bromocriptine was more effective than the nonselective dopamine receptor agonist apomorphine or the $\mathrm{D}_{1}$-selective agonist SKF38393. This is consistent with a putative $D_{2}$ receptor pharmacology (Cohen et al., 1992).

In contrast to its effect in expected light/actual darkness, dopamine at $10 \mu \mathrm{M}$ failed to increase the number of elongated photoreceptors when tested in expected darkness/actual dark-
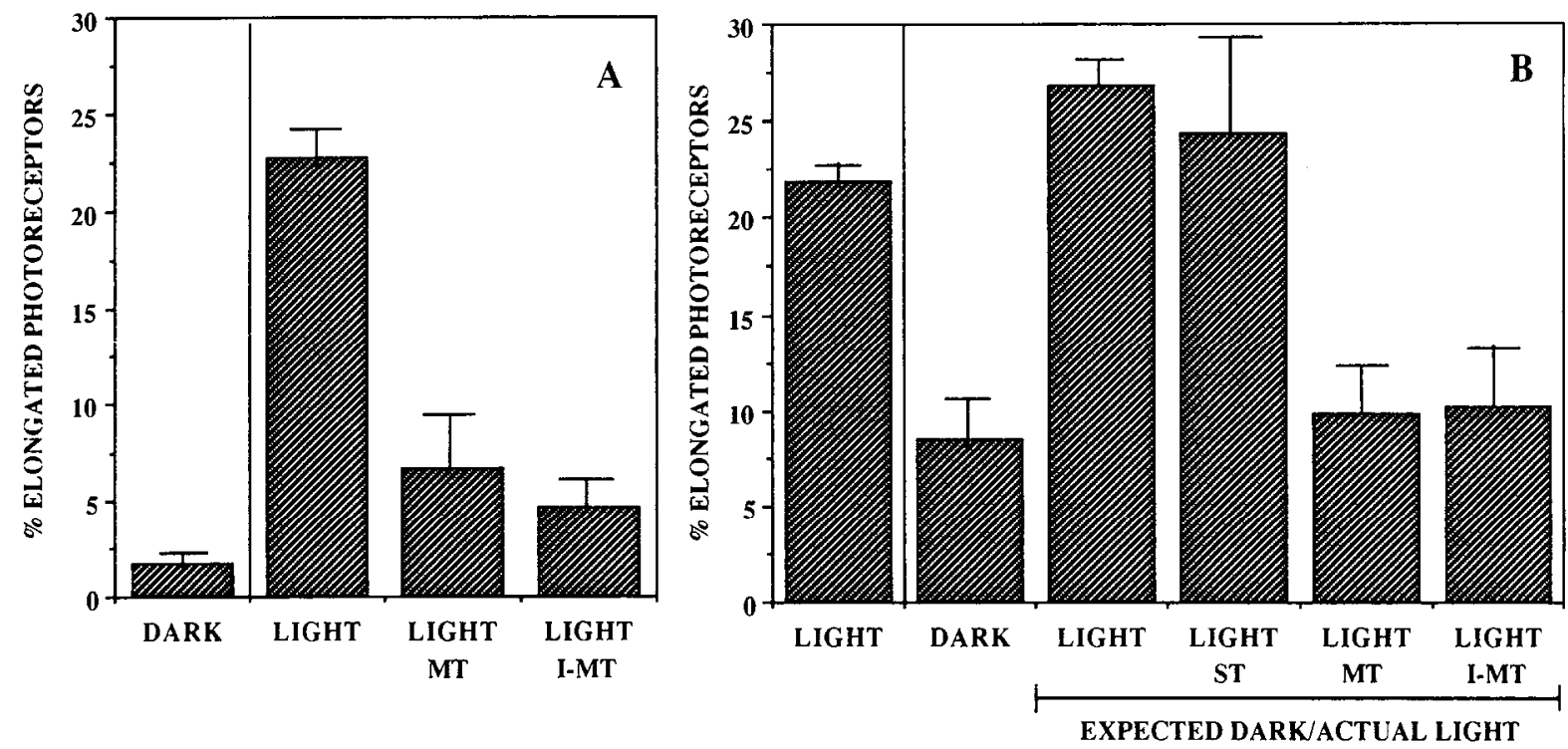

Figure 3. Effects of melatonin and melatonin receptor agonists on photomechanical responses in vitro. Cultures were treated with $1 \mu \mathrm{M}$ melatonin $(M T), 1 \mu \mathrm{M}$ 2-iodomelatonin $(I-M T)$, or $1 \mu \mathrm{M}$ serotonin $(S T)$ for $6 \mathrm{hr}$ and analyzed for the presence of elongated photoreceptors. $A$, Effects during expected light/actual light (experimental paradigm in Fig. $2 A$ ). $B$, Effects during expected darkness/actual light (experimental paradigm in Fig. $2 D$ ). The following differences were significant ( $\alpha=0.05$; see Materials and Methods): $A$, dark versus light, light versus MT, light versus I-MT; $B$, dark versus light, light versus MT, light versus I-MT. 
Table 2. Effects of dopamine (DA) agonists and antagonists on the frequency of elongated photoreceptors in vitro

\begin{tabular}{|c|c|c|c|c|c|}
\hline $\begin{array}{l}\text { Exptl. } \\
\text { para- } \\
\text { digm }^{a}\end{array}$ & $\begin{array}{l}\text { Expected } \\
\text { condition }\end{array}$ & $\begin{array}{l}\text { Actual } \\
\text { condition }\end{array}$ & $\begin{array}{l}\text { DA } \\
\text { agonist }\end{array}$ & $\begin{array}{l}\mathrm{DA} \\
\text { antagonist }\end{array}$ & $\begin{array}{l}\% \text { Elongated } \\
\text { photo- } \\
\text { receptors } \\
( \pm \mathrm{SD}) \\
\end{array}$ \\
\hline \multirow[t]{7}{*}{ A } & $\operatorname{Dark}^{h}$ & Dark $^{b}$ & & & $6.1(2.2)$ \\
\hline & Light & Light & & & $24.9(2.5)$ \\
\hline & Light & Light & & Fluperazine & $11.4(1.2)$ \\
\hline & Light & Light & & Spiperone & $13.4(2.6)$ \\
\hline & Light & Light & & Sulpiride $c$ & $14.5(1.0)$ \\
\hline & Light & Light & & Eticlopride ${ }^{c}$ & $15.9(3.2)$ \\
\hline & Light & Light & & Haloperidol $^{c}$ & $29.2(3.7)$ \\
\hline \multirow[t]{11}{*}{$\mathrm{C}$} & Light & Dark & & & $5.6(1.4)$ \\
\hline & Light & Dark & Dopamine $^{c}$ & & $26.6(6.0)$ \\
\hline & Light & Dark & Dopamine $^{c}$ & Sulpiride $^{d}$ & $9.4(1.8)$ \\
\hline & Light & Dark & Dopamine ${ }^{r}$ & Fluperazine $^{d}$ & $11.7(1.6)$ \\
\hline & Light & $D a r r^{k}$ & Dsp̈ănีiñ & 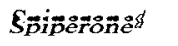 & $13.4\{3.1\}$ \\
\hline & Light & Dark & Dopamine $^{c}$ & Eticlopride $^{d}$ & $18.0(5.0)$ \\
\hline & Light & Dark & Dopamine $^{c}$ & Haloperidol $^{d}$ & $23.0(4.1)$ \\
\hline & Light & Dark & Bromocriptine $^{c}$ & & $17.6(5.1)$ \\
\hline & Light & Dark & Apomorphine ${ }^{c}$ & & $12.6(4.2)$ \\
\hline & Light & Dark & SKF38393 & & $11.7(2.2)$ \\
\hline & Light & Dark & Phenylephrine ${ }^{c}$ & & $3.7(0.9)$ \\
\hline \multirow[t]{4}{*}{ B } & Light $^{b}$ & Light $^{b}$ & & & $20.4(3.2)$ \\
\hline & Dark & Dark & & & $9.4(1.9)$ \\
\hline & Dark & Dark & Dopamine $^{c}$ & & $9.1(2.8)$ \\
\hline & Dark & Dark & Bromocriptinc & & $17.8(1.5)$ \\
\hline \multirow[t]{2}{*}{$\mathrm{D}$} & Dark & Light & & & $20.8(1.3)$ \\
\hline & Dark & Light & Spiperone $^{r}$ & & $4.0(1.4)$ \\
\hline
\end{tabular}

Neural retina cultures were examined after $6 \mathrm{hr}$ treatment with dopamine or dopamine agonist by counting the number of photoreceptors having an "elongated morphology" in triplicate 35 mm dishes. The table quantifies these elongated photoreceptors as a percentage of total photoreceptors. The following were significantly different $(\alpha=0.05$; see Materials and Methods): all dark versus light control comparisons, dark versus dopamine (paradigm C), dark versus bromocriptine (paradigms C and B), light versus all antagonists cxccpt halopcridol (paradigm A), dopamine versus dopamine plus all antagonists except haloperidol (paradigm C), and light versus spiperone (paradigm D).

a Experimental paradigm as described in Figure 2.

"Assayed prior to addition of drug/vehicle.

'Drug added at $10 \mu \mathrm{M}$.

"Drug added at $100 \mu \mathrm{M}$.

ness (Table 3), and elicited only a limited degree of elongation at $100 \mu \mathrm{M}$ under these conditions (data not shown). Bromocriptine $(10 \mu \mathrm{M})$ was equally effective in expected light/actual darkness and in expected darkness/actual darkness (Table 3). The difference between the effects of dopamine in the two experimental paradigms may imply that the relative susceptibility of photomechanical response to dopamine varies in a circadian manner.

Effects of dopamine antagonists and dbcAMP. Various dopamine antagonists were tested for their ability to inhibit the effects of dopamine, using two complementary assays (Table 2, and data not shown). At a concentration of $10 \mu \mathrm{M}$, the $\mathrm{D}_{2}$ selective antagonist sulpiride was more effective than the less selective antagonist haloperidol.

Since $D_{2}$ - and $D_{4}$-type dopamine receptors appear to be negatively coupled to adenylate cyclase in the retina (Cohen et al., 1992), cAMP analogs should counteract the effects of dopamine. Our results were consistent with this prediction, since $50 \mu \mathrm{M}$
dbcAMP prevented dopamine from eliciting light-adaptive photomechanical movements in expected light/actual darkness (Fig. $5 A$, Table 3).

Effects of $\mathrm{K}^{+}$-evoked depolarization. Depolarization by high extracellular $\left[\mathrm{K}^{+}\right]$was tested for effects on photomechanical responses by adding $20 \mathrm{mM} \mathrm{KCl}$ to culture medium before light onset. $\mathrm{KCl}$ significantly inhibited the response to light but responses could be restored by the addition of $10 \mu \mathrm{M}$ dopamine (Fig. 5B, Table 4). $\mathrm{KCl}$ was also effective during expected darkness/actual light, but the addition of $20 \mathrm{~mm} \mathrm{NaCl}$ had no effect in either condition (not shown).

\section{Analysis of endogenous dopaminergic activities}

Effects of dopamine antagonists upon photoreceptor responses to light. Dopamine receptor antagonists were also effective at inhibiting light-adaptive photomechanical movements (Table 2 ), with the selective $D_{2}$ antagonists sulpiride and spiperone being more effective at $10 \mu \mathrm{M}$ concentrations than the nonse- 


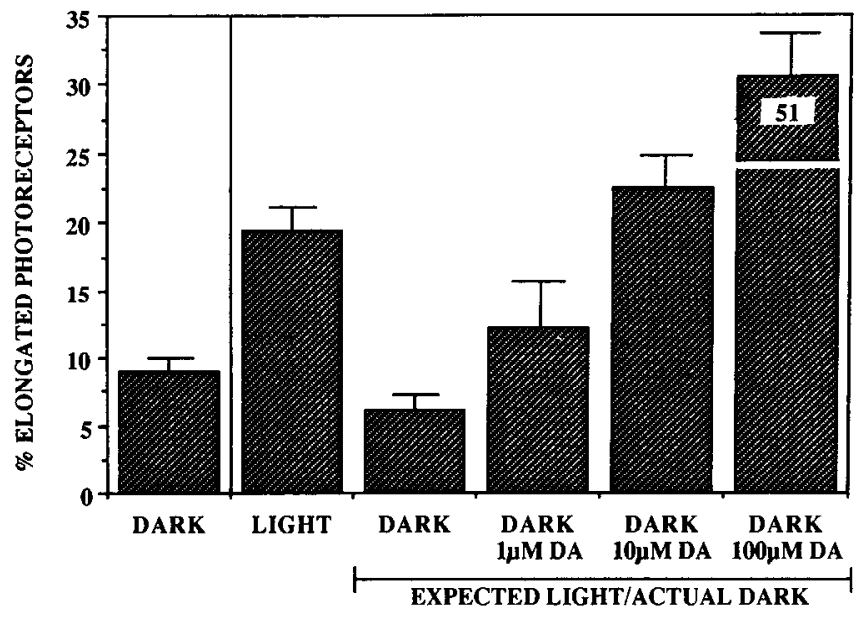

Figure 4. Efrects of dopamine $(D A)$ on photomechanical responses in vitro. Cultures were treated for $6 \mathrm{hr}$ and analyzed for the presence of elongated photoreceptors. Experimental paradigm in Figure $2 C$ is used (expected light/actual darkness). The following differences were significant $(\alpha=0.05$; see Materials and Methods): light versus dark, dark versus $10 \mu \mathrm{M}$ DA, dark versus $100 \mu \mathrm{M} \mathrm{DA}$

lective antagonist haloperidol. dbcAMP was also found to significantly attenuate the response of the cultures to light (Fig. 5A, Table 3 ). These results suggested that the signaling pathways for light and dopamine may converge at or before this second messenger regulatory system, and that dopamine receptor activation may be involved in light-adaptive photomechanical responses in vitro. This possibility raised questions about the existence of endogenous sources of dopamine in the cultures.

TH immunoreactivity. The potential existence of dopaminergic activities in the cultures was approached by investigating the presence of $\mathrm{TH}$, the rate-limiting enzyme for catecholamine synthesis (Levitt et al., 1965). Western blots of cultured retinal cell extracts, reacted with a polyclonal antibody against bovine $\mathrm{TH}$, showed two bands with relative molecular sizes of approximately 65 and $123 \mathrm{kDa}$, consistent with the expected behavior of TH monomers and dimers, respectively (Oka et al., 1983). Similar results were obtained with control samples of
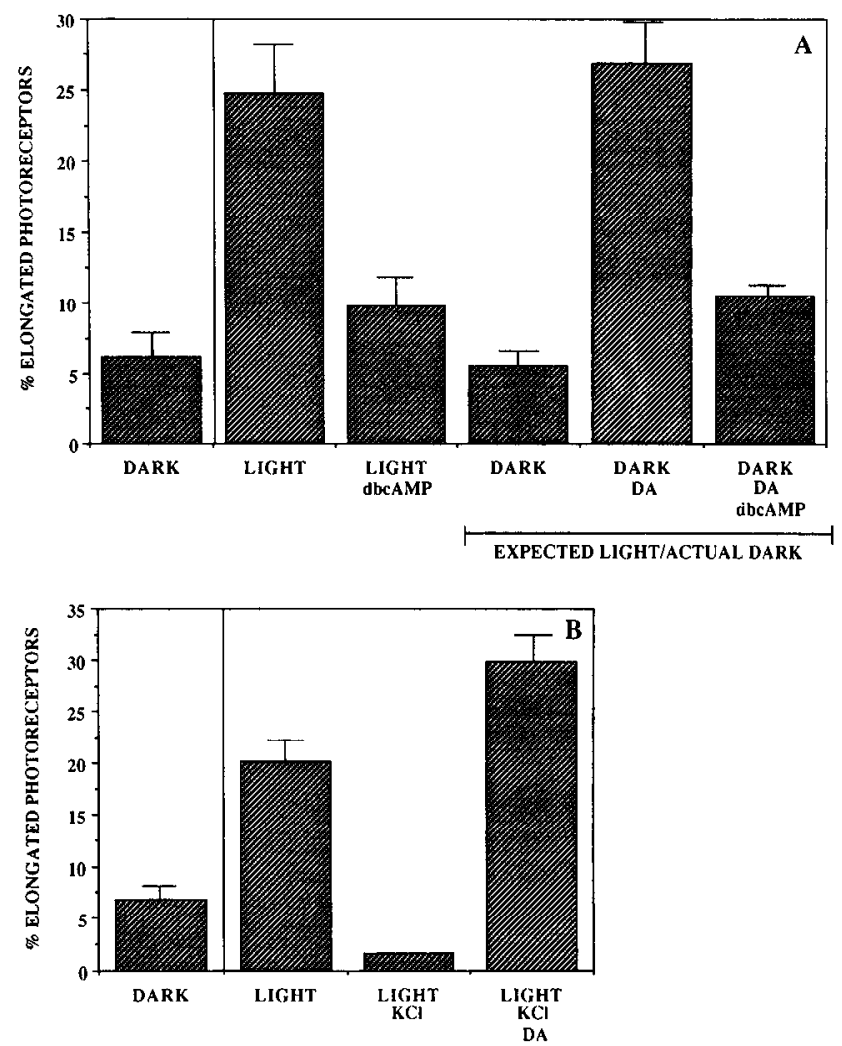

Figure 5. Effects of $50 \mu \mathrm{M}$ dibutyryl cyclic AMP $(d b c A M P)$ and $\mathrm{K}^{+}$ evoked depolarization on photomechanical responses in vitro. Cultures were treated for $6 \mathrm{hr}$ and then analyzed for the presence of elongated photoreceptors. $A$, Effects of dbcAMP on responses to light (experimental paradigm in Fig. $2 A$ ), and effects of dbcAMP on photoreceptor responses to $10 \mu \mathrm{M}$ dopanine $(D A)$ during expected light/actual darkness (experimental paradigm in Fig. 2C). B, Effects of $20 \mathrm{~mm} \mathrm{KCl}$ on photoreceptor responses to light, and their inhibition by $10 \mu \mathrm{M}$ dopamine $(D A)$ (experimental paradigm in Fig. $2 A$ ). The following differences were significant ( $\alpha=0.05$; see Materials and Methods): $A$, light versus dbcAMP, light versus dark, dark versus DA, DA versus DA-dbcAMP; $B$, dark versus light, light versus $\mathrm{KCl}, \mathrm{KCl}$ versus $\mathrm{KCl}-\mathrm{DA}$

Table 3. Effects of dbcAMP on light- and dopamine-stimulated photomechanical responses in vitro

\begin{tabular}{|c|c|c|c|c|c|c|c|c|c|}
\hline \multirow{2}{*}{$\begin{array}{l}\text { Exptl. } \\
\text { para- } \\
\text { digm }\end{array}$} & \multirow[b]{2}{*}{$\begin{array}{l}\text { Expected } \\
\text { condition }\end{array}$} & \multirow[b]{2}{*}{$\begin{array}{l}\text { Actual } \\
\text { condition }\end{array}$} & \multirow[b]{2}{*}{$\begin{array}{l}\text { Dopa- } \\
\text { mine }^{h}\end{array}$} & \multirow[b]{2}{*}{$\begin{array}{l}\text { dbc- } \\
\text { AMP }\end{array}$} & \multicolumn{5}{|c|}{ Photoreceptor length distribution (\%) } \\
\hline & & & & & $\begin{array}{l}10-14 \\
\mu \mathrm{m}\end{array}$ & $\begin{array}{l}15-19 \\
\mu \mathrm{m}\end{array}$ & $\begin{array}{l}20-24 \\
\mu \mathrm{m}\end{array}$ & $\begin{array}{l}25-29 \\
\mu \mathrm{m}\end{array}$ & $\begin{array}{l}>30 \\
\mu \mathrm{m}\end{array}$ \\
\hline \multirow[t]{3}{*}{ A } & Dark $^{d}$ & Dark $^{d}$ & & & 31.1 & 55.6 & 11.1 & 2.2 & 0 \\
\hline & Light & Light & & & 6.7 & 46.7 & 31.1 & 11.1 & 4.4 \\
\hline & Light & Light & & $\mathrm{x}$ & 28.9 & 40.0 & 31.1 & 0 & 0 \\
\hline \multirow[t]{3}{*}{$\mathrm{C}$} & Light & Dark & & & 46.7 & 33.3 & 17.8 & 2.2 & 0 \\
\hline & Light & Dark & $\mathrm{x}$ & & 13.3 & 48.9 & 20.0 & 17.8 & 0 \\
\hline & Light & Dark & $\mathrm{X}$ & $\mathrm{X}$ & 33.3 & 51.1 & 6.7 & 8.9 & 0 \\
\hline
\end{tabular}

Neural retina cultures were examined after a $6 \mathrm{hr}$ treatment with dopamine and/or dbcAMP. Forty-five photoreceptors were measured for each condition (15 in each of three $35 \mathrm{~mm}$ dishes), and were assigned to $5 \mu \mathrm{m}$ bins based on length. The table shows distributions of these lengths according to illumination condition and drug treatment.

" Experimental paradigm as described in Figure 2.

${ }^{b}$ Drug added at $10 \mu \mathrm{m}$.

- Drug added at $50 \mu \mathrm{M}$.

${ }^{d}$ Assayed prior to addition of drug/vehicle. 
1

\section{3}

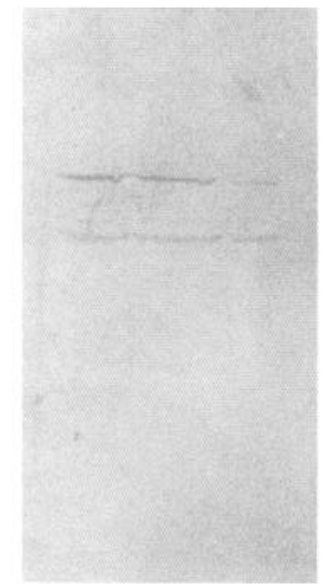

456

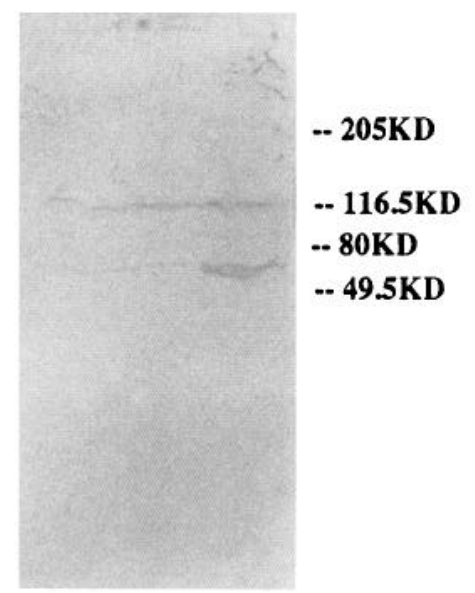

Figure 6. TH antiserum immunoblot. Lanes 1 and 2, chick neural retina cultures harvested during dark and light periods, respectively, on div 6; lane 3, cultures treated with 6-OHDA at 4 div, harvested during a light period on div 6; lane 4, E16 chick retina; lane 5, postnatal day 5 (P5) chick retina; lane 6, P5 chick heart. Positions of molecular size standards are indicated to the right.

tissues known to contain $\mathrm{TH}$, such as posthatch chicken heart and retina, while blots processed with control, nonimmune serum failed to show detectable bands (not shown).

The bands of TH-immunoreactive materials were reduced in Western blots of cultures treated at 3 div with $7 \mu \mathrm{M}$ 6-OHDA, which is toxic for dopaminergic neurons (Johnsson et al., 1975; Braisted and Raymond, 1992) and attenuates in vitro photomechanical movement (see below). Higher 6-OHDA concentrations could not be studied due to nonspecific cytotoxic effects. We observed no apparent differences in the amount of THimmunoreactive material in cultures harvested during the dark as compared to the light phases of the cycle (Fig. 6).

Inhibition of photomechanical movement by drugs that attenuate dopamine synthesis. AMPT, a TH inhibitor, eliminated almost completely the light-induced appearance of elongated photoreceptors in 5-6 div cultures exposed to the drug since in vitro day 4 (Fig. $7 A$ ). The occurrence of photoreceptor elongation when exogenous dopamine was added at 6 div to some of these AMPT-treated cultures indicated that AMPT did not have deleterious effects upon the photoreceptors themselves. In a second group of experiments, complete attenuation of photomechanical responses was observed at 5-6 div in cultures treated at 3 div with $7 \mu \mathrm{M}$ 6-OHDA (Fig. 7B). Responsiveness to exogenous dopamine could not be studied in this case due to toxic effects apparently resulting from the exposure to both 6-OHDA and dopamine (data not shown). However, photoreceptor elongation could be elicited in the 6-OHDA-treated cultures at 6 div by cytochalasin $\mathrm{D}$, which has been shown to trigger photoreceptor elongation by inhibiting actin-dependent contractile mechanisms (Madreperla and Adler, 1989; D. L. Stenkamp and R. Adler, unpublished observations).

$\mathrm{Na}^{+}$-dependent ${ }^{3} \mathrm{H}$-dopamine accumulation. The presence of $\mathrm{Na}^{+}$-dependent uptake mechanisms for dopamine is characteristic of dopaminergic neurons. Preliminary experiments indicated that ${ }^{3} \mathrm{H}$-dopamine accumulation was more readily measured when $\mathrm{Co}^{2+}$ was substituted for $\mathrm{Ca}^{2+}$ in the incubation medium, probably due to inhibition of $\mathrm{Ca}^{2+}$-dependent, exocytotic release mechanisms (Paes de Carvalho et al., 1990; Efthimiopoulos et al., 1991).

${ }^{3} \mathrm{H}$-dopamine accumulation in $\mathrm{Ca}^{2+}$-free, $\mathrm{Co}^{2+}$-supplemented buffers (Fig. $8 \mathrm{~A}$ ) was concentration dependent, and Eadie-Hofstee analysis revealed a low-affinity, high-capacity transport component and a high-affinity, low-capacity transport component. This resembles findings in rat cerebellum, striatum, and frontal cortex (Efthimiopoulos et al., 1991). Cellular accumulation was reduced by roughly $75 \%$ under $\mathrm{Na}^{+}$-free conditions (as compared to $\mathrm{Ca}^{2+}$-free conditions). Autoradiographic analysis (Fig. $8 B$ ) showed heavy labeling of multipolar neurons and of round, morphologically undifferentiated cells in the presence, but not in the absence, of $\mathrm{Na}^{+}$ions (not shown). Scattered silver grains were associated with photoreceptors under both $\mathrm{Na}^{+}$. containing and $\mathrm{Na}^{+}$-free conditions, suggesting that they may
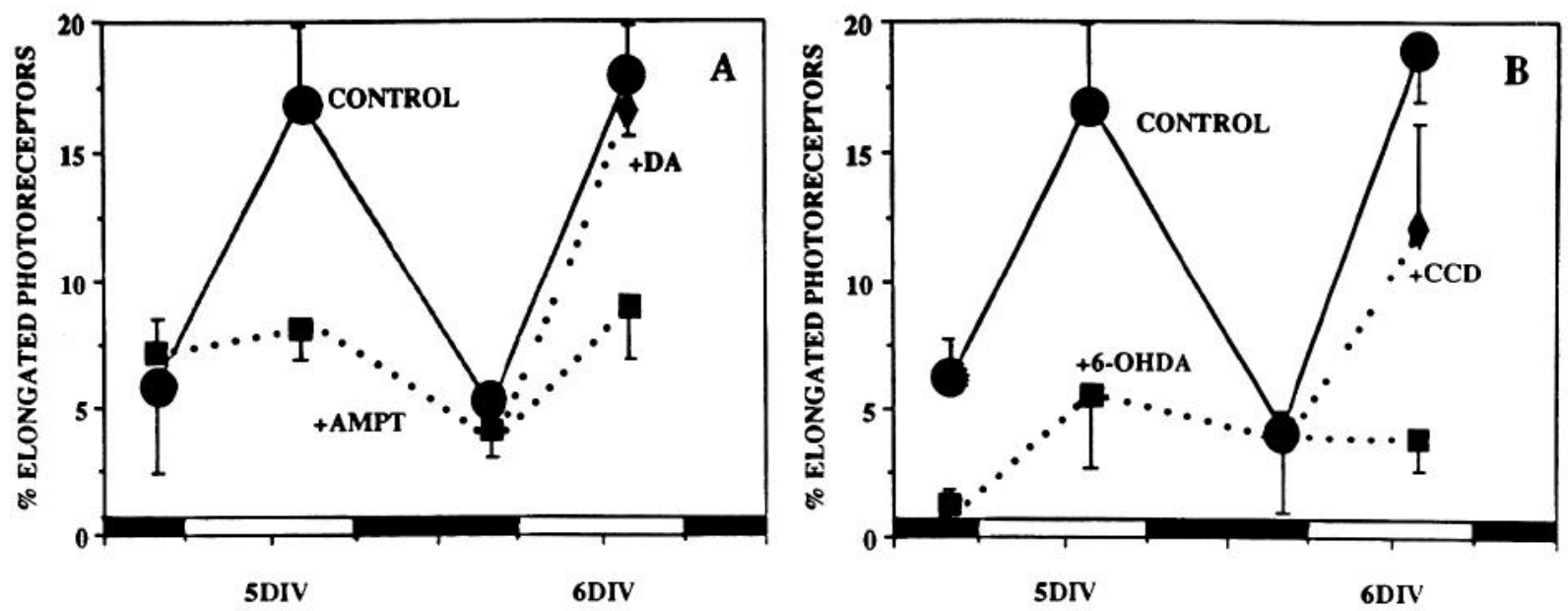

Figure 7. Effects of dopamine synthesis inhibitors on the frequency of elongated photoreceptors in culture (expressed as a percentage of total photoreceptors). Solid and open bars at the bottom indicate dark and light periods, respectively (see Materials and Methods). A, Circles, control (vehicle added at 4 div); squares, $50 \mu \mathrm{M} \alpha$-methyl-p-tyrosine (AMPT) added at 4 div; diamond, AMPT at 4 div and $10 \mu \mathrm{M}$ dopamine (DA) at 6 div. B, Circles, control (vehicle added at 4 div); squares, $7 \mu \mathrm{M}$ 6-hydroxydopamine (6-OHDA) added at 4 div; diamond, 6-OHDA at 4 div and $2 \mu_{\mathrm{M}}$ cytochalasin $\mathrm{D}(C C D)$ at 6 div. In addition to all light versus dark comparisons for controls, the following differences were significant $(\alpha=$ 0.05 ; see Materials and Methods): $A$, light control versus light AMPT, light AMPT versus light AMPT-DA; $B$, light control versus light 6-OHDA, light 6-OHDA versus light 6-OHDA-CCD. 

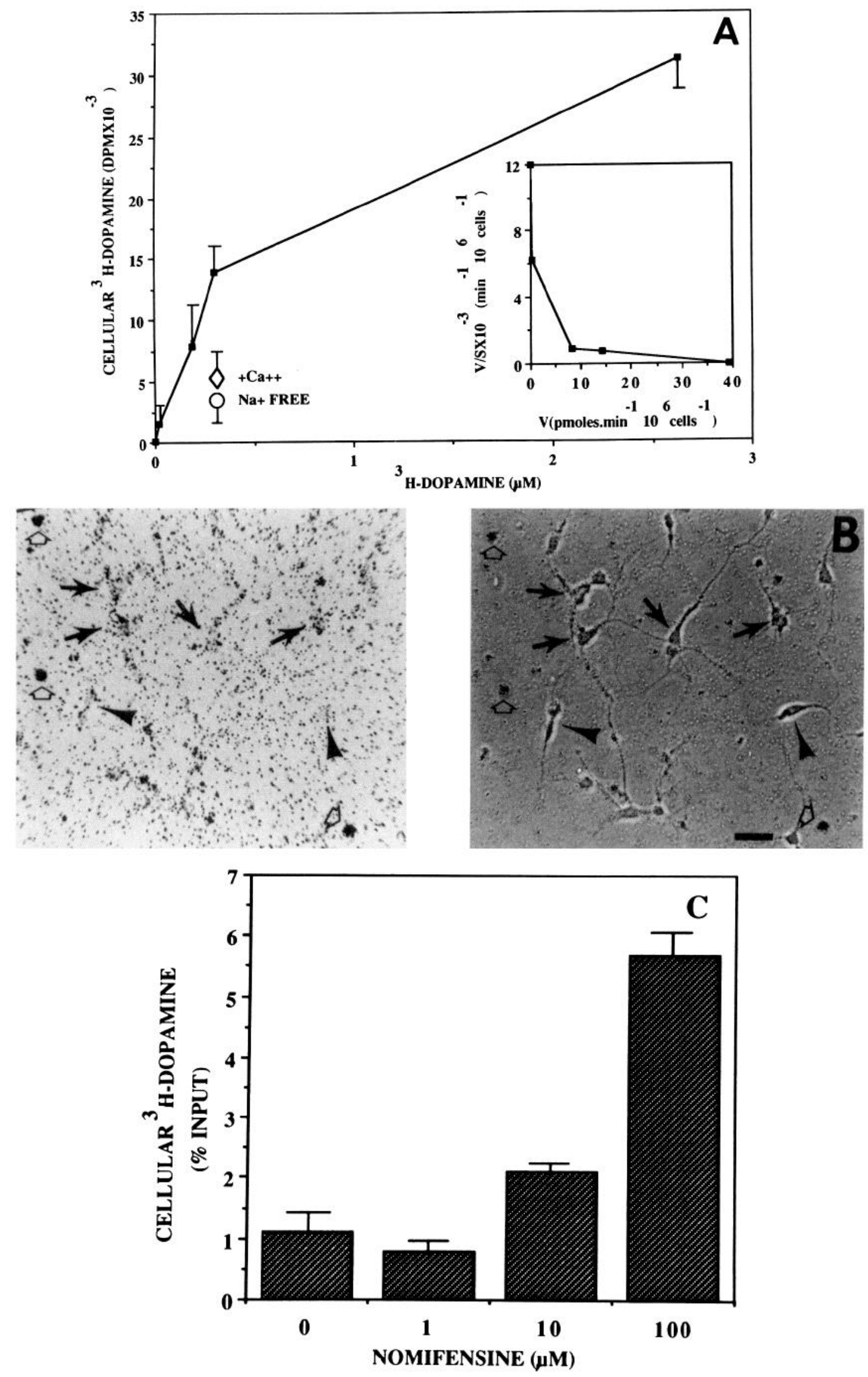

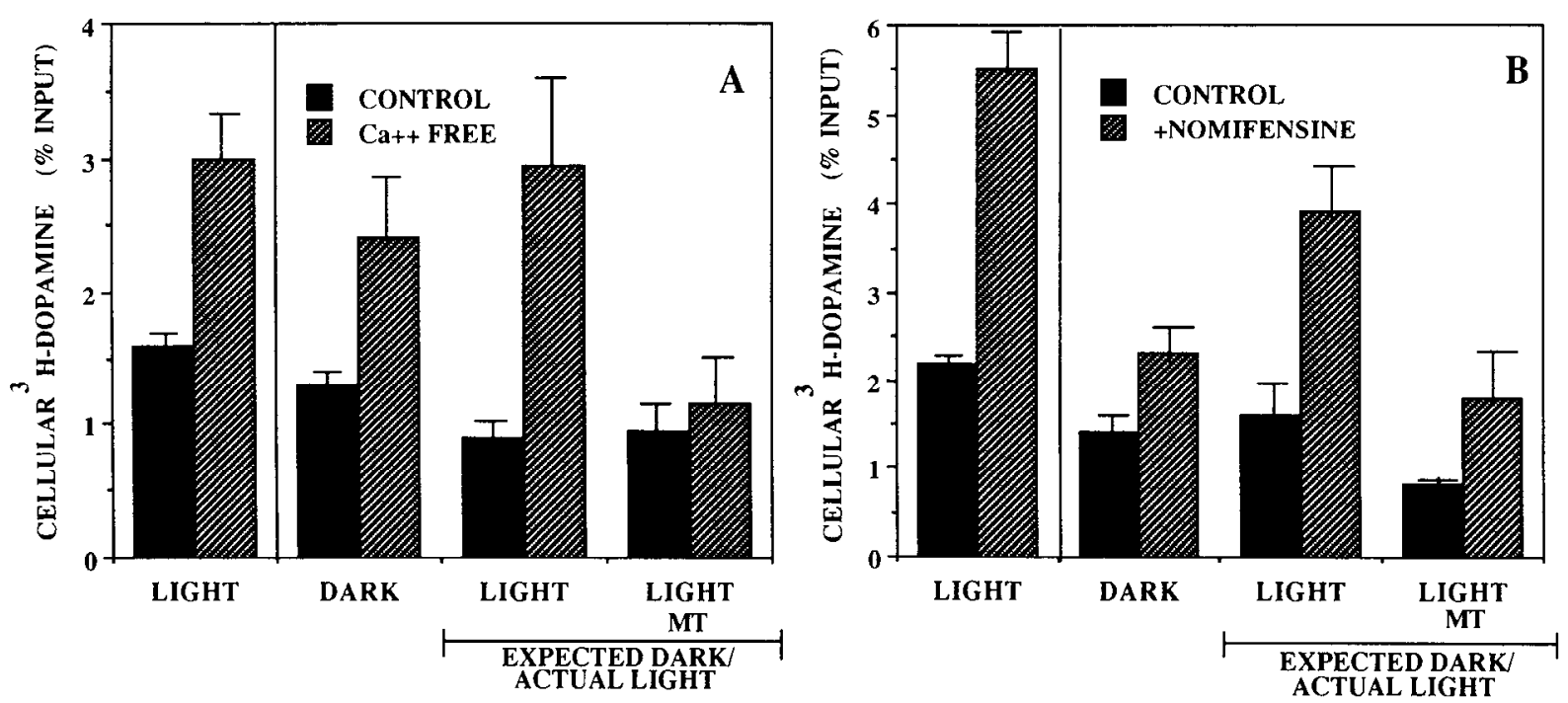

Figure 9. A, Effects of $\mathrm{Ca}^{2+}$ on intracellular accumulation of ${ }^{3} \mathrm{H}$-dopamine in the constant presence of nomifensine under various conditions. Experimental design in Figure $2 D$ is used, showing increased accumulation in the absence of $\mathrm{Ca}^{2+}$, which is inhibited by $1 \mu \mathrm{M}$ melatonin $(M T)$ during expected darkness/actual light. $B$, Effects of nomifensine on intracellular accumulation of ${ }^{3} \mathrm{H}$-dopamine in the constant absence of $\mathrm{Ca}^{2+}$, under various conditions. Experimental design in Figure $2 D$ is used, showing increased accumulation in the presence of nomifensine, which is inhibited by expected darkness/actual darkness, and by $1 \mu \mathrm{M}$ melatonin $(M T)$ during expected darkness/actual light. The following differences were significant $\left(\alpha=0.05\right.$; see Materials and Methods): $A$, for all conditions, $\mathrm{Ca}^{2+}$-containing versus $\mathrm{Ca}^{2+}$-free; $B$, for all conditions except $\mathrm{MT},-\mathrm{NOMI}$ versus + NOMI

represent background labeling. We have not determined whether the nonphotoreceptor neurons that accumulate ${ }^{3} \mathrm{H}$-dopamine are also those that take up glutamate, GABA, or taurine under similar conditions (Adler, 1983; Pessin and Adler, 1985; Politi and Adler, 1987). It must be noted, however, that the coexistence of uptake mechanisms for as many as three different neurotransmitters has been demonstrated in these cultured cells (Pessin and Adler, 1985).

A nomifensine-sensitive dopamine transporter has been described that can transport dopamine both into (Efthimiopoulos et al., 1991) and out of cells (Lonart and Zigmond, 1990; Jacocks and Cox, 1992). In our cultures, nomifensine stimulated very effectively the accumulation of ${ }^{3} \mathrm{H}$-dopamine in the cultures in a dose-dependent manner (Fig. $8 \mathrm{C}$ ). By analogy with results in other tissues (Lonart and Zigmond, 1990; Jacocks and Cox, 1992), therefore, it appears that the nomifensine-sensitive dopamine transporter may be functioning as a nonexocytotic dopamine release mechanism in cultured retinal cells. This possibility is further explored in the Discussion.

Effect of light and melatonin on dopamine release. The findings reported in the preceding section provided indirect evidence for the existence of two putative dopamine release mechanisms in the cultures: one appeared to be $\mathrm{Ca}^{2+}$ dependent and $\mathrm{Co}^{2+}$ sensitive, whereas the second appeared to involve the nomifensine-sensitive dopamine transporter. Direct investigation of their relative contributions was somewhat hampered by the susceptibility of low-density retinal cultures to damage by protocols involving repeated and quick washes. As an alternative, we estimated $\mathrm{Ca}^{2+}$-dependent release by measuring intracellular accumulation of ${ }^{3} \mathrm{H}$ radioactivity after incubating cultures with ${ }^{3} \mathrm{H}$-dopamine in the presence of $10 \mu \mathrm{M}$ nomifensine (to prevent transporter-dependent release), and in the presence or absence of $\mathrm{Ca}^{2+}$. As shown in Figure $9 A$, intracellular accumulation of ${ }^{3} \mathrm{H}$-dopamine was higher under $\mathrm{Ca}^{2+}$-free conditions in expected light/actual light, expected darkness/actual darkness, and expected darkness/actual light conditions. However, the effects of $\mathrm{Ca}^{2+}$-free medium were abolished when expected darkness/actual light cultures were simultaneously treated with $1 \mu \mathrm{M}$ melatonin.

The reciprocal experiment involved incubating cultures with ${ }^{3} \mathrm{H}$-dopamine in the absence of $\mathrm{Ca}^{2+}$ (to block $\mathrm{Ca}^{2+}$-dependent release), and in the presence or absence of nomifensine. As shown in Figure $9 B$, intracellular accumulation of ${ }^{3} \mathrm{H}$-dopamine was increased approximately threefold in the presence of nomifensine in expected light/actual light, and over twofold in expected darkness/actual light conditions. Smaller differences were observed in expected darkness/actual darkness cultures. Melatonin at $1 \mu \mathrm{m}$ caused reductions in dopamine accumulation in expected darkness/actual light conditions, which were particularly evident in the presence of nomifensine.

Nomifensine reversibly inhibits light-dependent photomechanical responses. Since nomifensine appears to block dopamine release in vitro, it should be expected to attenuate light-induced photoreceptor elongation if, as postulated, endogenous sources

Figure 8. Cellular accumulation of ${ }^{3} \mathrm{H}$-dopamine. A, Dose-dependent accumulation under $\mathrm{Ca}^{2+}$-free conditions. Open symbols indicate accumulation in the presence of $\mathrm{Ca}^{2+}(\diamond)$ and in $\mathrm{Na}^{2+}$-free conditions $(O)$ at a concentration of $0.3 \mu \mathrm{M}{ }^{3} \mathrm{H}$-dopamine in the medium. Inset, EadieHofstee analysis of ${ }^{3} \mathrm{H}$-dopamine uptake, showing a low-affinity, high-capacity uptake component and a high-affinity, low-capacity uptake component. $B$, Autoradiography of cultures incubated with ${ }^{3} \mathrm{H}$-dopamine in the absence of $\mathrm{Ca}^{2+}$. Panels show the same photographic field examined under bright-field and phase-contrast optics showing silver grains concentrated over morphologically undifferentiated cells (open arrows) and neurons (solid arrows), but not over photoreceptors (arrowheads). Scale bar, $10 \mu \mathrm{M}$. C, Effect of nomifensine $(N O M I)$ on accumulation of cellular ${ }^{3} \mathrm{H}$ dopamine. The following were significantly different $\left(\alpha=0.05\right.$; see Materials and Methods): $A$, for $0.3 \mu \mathrm{M}, \mathrm{Ca}^{2+}$-free versus $\mathrm{Ca}^{2+}-\mathrm{containing}, \mathrm{Na}^{+}-$ free versus $\mathrm{Ca}^{2+}$-free; $C$, control versus $10 \mu \mathrm{M}$ NOMI, control versus $100 \mu \mathrm{M}$ NOMI. 


\begin{tabular}{|c|c|c|c|c|c|c|c|c|c|}
\hline \multirow{2}{*}{$\begin{array}{l}\text { Exptl. } \\
\text { para- } \\
\text { digm }^{a}\end{array}$} & \multirow[b]{2}{*}{$\begin{array}{l}\text { Expected } \\
\text { condition }\end{array}$} & \multirow[b]{2}{*}{$\begin{array}{l}\text { Actual } \\
\text { condition }\end{array}$} & \multirow[b]{2}{*}{$\mathrm{KCl}^{\prime}$} & \multirow[b]{2}{*}{$\begin{array}{l}\text { Dopa- } \\
\text { miner }\end{array}$} & \multicolumn{5}{|c|}{ Photoreceptor length distribution (\%) } \\
\hline & & & & & $\begin{array}{l}10-14 \\
\mu \mathrm{m}\end{array}$ & $\begin{array}{l}15-19 \\
\mu \mathrm{m}\end{array}$ & $\begin{array}{l}20-24 \\
\mu \mathrm{m}\end{array}$ & $\begin{array}{l}25-29 \\
\mu \mathrm{m}\end{array}$ & $\begin{array}{l}>30 \\
\mu \mathrm{m}\end{array}$ \\
\hline \multirow[t]{4}{*}{ A } & Dark & $\operatorname{Dark}^{d}$ & & & 35.6 & 48.9 & 24.4 & 0 & 0 \\
\hline & Dark & Light & & & 8.9 & 31.1 & 31.1 & 17.8 & 11.1 \\
\hline & Dark & Light & $\mathrm{X}$ & & 51.1 & 28.9 & 15.6 & 4.4 & 0 \\
\hline & Dark & Light & $\mathrm{X}$ & $\mathrm{X}$ & 6.7 & 24.4 & 35.6 & 11.1 & 22.2 \\
\hline
\end{tabular}

Neural retina cultures were examined after a $6 \mathrm{hr}$ treatment with $\mathrm{KCl}$ and/or dopamine by measuring 45 photoreceptors for each condition ( 15 in each $35 \mathrm{~mm}$ dish); photoreceptors were assigned to $5 \mu \mathrm{m}$ bins based on length. The table shows distributions of these lengths according to illumination conditions and drug treatment.

${ }^{a}$ Experimental paradigm as described in Figure 2.

${ }^{b}$ Drug added at $20 \mu \mathrm{M}$.

c Drug added at $10 \mu \mathrm{M}$.

${ }^{d}$ Assayed prior to addition of $\mathrm{drug} /$ vehicle.

of dopamine mediate these effects of light. As shown in Figure $10,10 \mu \mathrm{M}$ nomifensine did indeed reduce significantly, by approximately $50 \%$, the frequency of elongated photoreceptors in light-exposed cultures. Moreover, concomitant treatment of the cultures with nomifensine and $10 \mu \mathbf{M}$ dopamine restored photoreceptor elongation, indicating that nomifensine did not interfere directly with photoreceptor responsiveness to dopamine. Nomifensine effects upon photoreceptor elongation were similar in expected light/actual light and expected darkness/actual light conditions; no effects were detected upon dark-adaptive responses (not shown). Theoretically, elimination of $\mathrm{Ca}^{2+}$ ions from the culture medium should also inhibit light-dependent photomechanical responses by inhibiting $\mathrm{Ca}^{2+}$-dependent dopamine release. This hypothetical mechanism could not be verified experimentally because of the deleterious effects of $\mathrm{Ca}^{2+}$ free, EDTA-containing medium upon the cultured cells during the $6 \mathrm{hr}$ assay period necessary for these studies.

\section{Discussion}

\section{Effects of ncuromodulators in vitro}

The experiments aimed at analyzing the susceptibility of photomechanical responses to regulation by neuromodulators can be summarized as follows: (1) light-dependent, rhythmic photomechanical responses of cultured embryonic photoreceptors can be regulated by exogenous neuromodulatory agonists and antagonists; (2) melatonin and its receptor agonist inhibit the effects of light and mimic the effects of darkness; (3) dopamine and its receptor agonists mimic the effects of light with a $\mathrm{D}_{2}-$ type pharmacology; (4) dopamine receptor antagonists inhibit the effects of dopamine as well as those of light, with a $D_{2}$-type pharmacology; (5) the cyclic nucleotide analog dbcAMP has similar inhibitory effects upon dopamine- and light-induced photoreceptor elongation; and (6) $\mathrm{K}^{+}$-evoked depolarization has dark-adaptive effects upon photomechanical responses.

Taken together, these experiments suggest that the cultured cells have appropriate receptors and second-messenger signal systems that mediate the effects of exogenous neuromodulators. Although the cellular distribution of these receptors remains undetermined, possible involvement of RPE and Müller cells can be excluded, since they are not present in the cultures. We hypothesize that photoreceptors are likely sites for dopamine $\mathrm{D}_{2}$ receptors for reasons of parsimony; this would also be consistent with the tentative localization to cultured chick photoreceptors of $\mathrm{D}_{2}$ receptor-regulated $N$-acetyltransferase activity
(Iuvone et al., 1990), and with studies of melatonin release from isolated Xenopus photoreceptors (Cahill and Besharse, 1993). In the retina, in vivo, $\mathrm{D}_{2}$-like receptors have been identified with radioligand binding in the outer nuclear layer (Zarbin et al., 1986), as well as in rod outer segments (Brann and Jelsena, 1985). Melatonin receptors have been detected primarily in the inner plexiform layer of the retina in vivo, suggesting a distribution that includes amacrine or interplexiform cells (Dubocovich, 1988). Their in vitro distribution remains unknown. Activation of melatonin receptors has been shown to occur at nanomolar or even subnanomolar concentrations. However, a $100 \mathrm{~nm}$ concentration was needed to elicit a dark-adaptive response in chick retinal cultures, possibly due to the susceptibility of melatonin to oxidation. This is consistent with the observation that higher melatonin concentrations were needed to activate photoreceptor disk shedding in the absence than in the presence of the antioxidant ascorbic acid (Besharse and Dunis, 1983; Besharse et al., 1984).

Although rhythmic photomechanical responses did not ap-

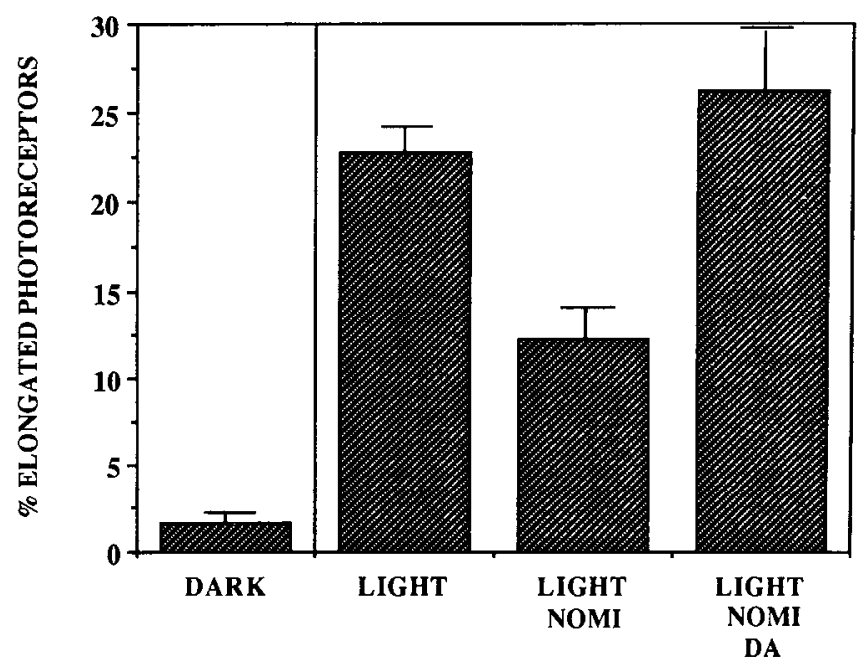

Figure 10. Effects of $10 \mu \mathrm{M}$ nomifensine (NOMI) on photomechanical movement in vitro. Cultures were treated for $6 \mathrm{hr}$ and examined for the presence of elongated photoreceptors. Experimental paradigm in Figure $2 A$ is used, showing effects during expected light/actual light. $D A, 10$ $\mu \mathrm{M}$ dopamine added. The following differences were significant $(\alpha=$ 0.05 ; see Materials and Methods): dark versus light, light versus NOMI, NOMI versus NOMI-DA. 


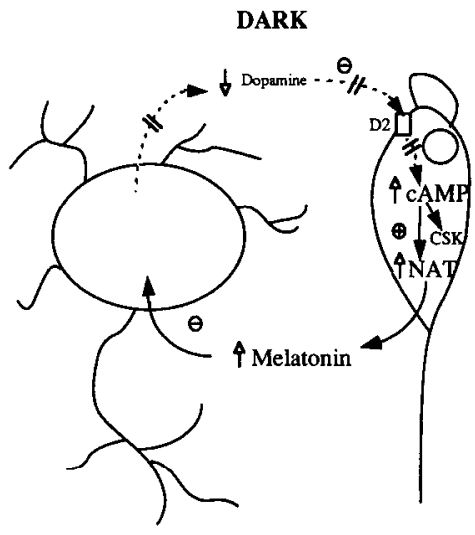

A

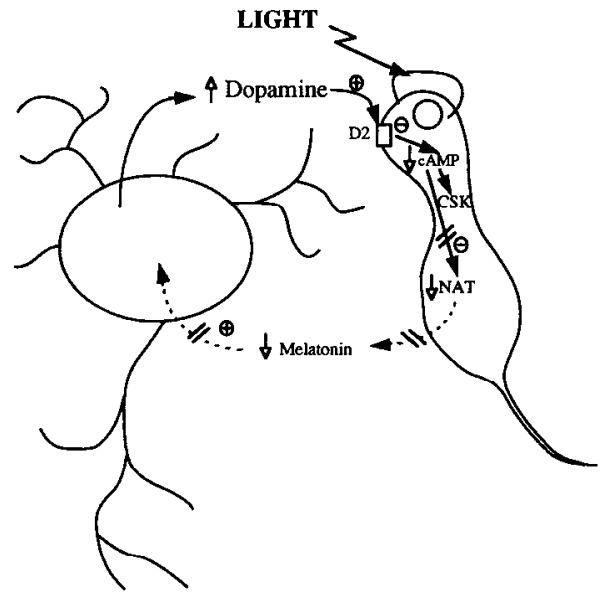

B
Figure 11. Model for regulation of in vitro photomechanical responscs to dark $(A)$ and light $(B) . D_{2}, \mathrm{D}_{2}$-type dopamine receptor; $C A M P$, cyclic AMP; $N A T$, serotonin $N$-acetyltransferase; $C S K$, cytoskeleton. See Discussion for explanation. pear circadian, it is noteworthy that dopamine was more effective in mimicking the effects of light during expected light/actual darkness conditions than during expected darkness/actual darkness. The relative lack of effects during expected darkness/actual darkness could imply that some cell properties, such as sensitivity to dopamine, change in a circadian manner. Two possible mechanisms would be downregulation of dopamine receptors and/or upregulation of dopamine catabolism during expected darkness. Relevant to this discussion is the observation that bromocriptine, a $\mathrm{D}_{2}$ agonist, was effective at eliciting photoreceptor elongation during expected darkness. Furthermore, dopamine receptor antagonists inhibited the effects of light in both cxpected light and cxpected darkness. At present, the data do not allow us to discriminate between the two postulated mechanisms.

The dopamine receptors involved in the regulation of photomechanical responses in vitro appear to be of the $\mathrm{D}_{2}$ or $\mathrm{D}_{4}$ type, as suggested by the relative effects of both agonists and antagonists. However, the concentrations of dopamine needed for an effect greatly exceeded those usually needed to activate $D_{2}$-type receptors. As in the case of melatonin (see above), this discrepancy may be explained by the susceptibility of dopamine to oxidation in solution. Previous studies showing effects of dopamine at lower concentrations (Pierce and Besharse, 1985; Dearry and Burnside, 1986) were carried out in the presence of ascorbic acid, an antioxidant that could not be used in our culture medium due to deleterious effects upon the cells. It is also noteworthy that Pierce and Besharse (1985) observed that high concentrations of dopamine $(50 \mu \mathrm{M})$ were necessary to elicit maximal responses in Xenopus eyecups. Additional evidence for the participation of $D_{2}$-type receptors in the chick retinal cultures is provided by the observation that dbcAMP counteracts the effects of both light and dopamine; the latter decreases cAMP accumulation when acting on $\mathrm{D}_{2}$ - or $\mathrm{D}_{4}$-type receptors (Iuvone, 1986; Cohen et al., 1992). While this interpretation assumes that cyclic nucleotides act only as intracellular second messengers, it is noteworthy that a recent report suggested that cAMP may act also as an intercellular first messenger in the retina (Burnside and Garcia, 1992).

\section{$A$ "paracrine network" in vitro}

The finding that dopamine antagonists and dbcAMP inhibited both the effects of dopamine and those of light is consistent with a convergence of dopamine and light at the level of the $D_{2}$ dopamine receptor or its signal transduction pathway. This hypothetical mechanism would require the presence of endogenous sources of dopamine in the cultures. Our investigation of this hypothetical mechanism can be summarized as follows: (1) dopamine $\mathrm{D}_{2}$ receptor antagonists inhibit photoreceptor responses to light; (2) Western blot analysis shows the presence of $\mathrm{TH}$ like immunoreactivity in extracts of the cultured cells; (3) THlike immunoreactivity is less abundant in cultures treated with 6-OHDA, a neurotoxin specific for dopaminergic cells; (4) photomechanical responses to light are attenuated after treatment of the cultures with 6-OHDA or with AMPT, an inhibitor of TH activity; (5) nonphotoreceptor cell types (e.g., multipolar ncurons and morphologically undifferentiatcd cclls) accumulate ${ }^{3} \mathrm{H}$-dopamine under $\mathrm{Ca}^{2+}$-free conditions, in an $\mathrm{Na}^{+}$-dependent manner; (6) nomifensine, an inhibitor of the dopamine transporter, affects both the intracellular accumulation of dopamine and photoreceptor elongation in response to light; and (7) intracellular accumulation of ${ }^{3} \mathrm{H}$-dopamine can be regulated by light and by melatonin, at least in part through a reduction in dopamine release.

Taken together, these findings are consistent both with the presence of dopaminergic cells in the cultures, and with their involvement in the regulation of photomechanical responses in vitro. Moreover, the data suggest the development of a "paracrine network" in the cultures, whereby specific cell types communicate information regarding light conditions in the external environment, resulting in the coordination of complex responses such as photomechanical movements. A hypothetical model, consistent with results from the literature and our own data, is summarized in Figure 11. This working model proposes that light and melatonin have opposite effects upon the efflux of dopamine from nonphotoreceptor cells into the extracellular environment and that light, initially detected by the photoreceptor cell, also causes a decrease in melatonin synthesis and release. In the following paragraphs we will discuss the premises on which this model is based, including (1) that photoreceptors are the light-sensitive cells in the cultures; (2) that cultured photoreceptors are a source of melatonin, which can be regulated by dopamine and/or by light; (3) that cultured nonphotoreceptor neurons (and/or morphologically undifferentiated cells) are a source of dopamine, which can be regulated indirectly by light and/or directly by melatonin; and (4) that these cell types communicate with each other in vitro by regulating levels of melatonin and dopamine in their environment. 
Photoreceptors as the light-sensitive cell in vitro. Cultured photoreceptors resemble their in vivo counterparts in many respects, including structural and molecular polarity, the accumulation of $\mathrm{Na}^{+}, \mathrm{K}^{+}$-ATPase in the inner segment plasma membrane, and the presence of an inner segment lipid droplet (a characteristic of cone photoreceptors and some embryonic photoreceptors). Of particular relevance to this discussion is the expression of opsin-immunoreactive materials (Adler, 1986; Madreperla and Adler, 1989; Madreperla et al., 1989; reviewed in Adler, 1993) which, however, would not be sufficient for phototransduction in the absence of the visual pigment chromophore 11-cis retinaldehyde (Hubbard and Wald, 1952). While retinyl acetate and retinol are present in the culture medium used for these experiments, 11-cis retinaldehyde is not (Stenkamp and Adler, unpublished observations). This raises questions regarding the source of chromophore in the cultures, which are grown in the absence of RPE. The RPE is considered the primary site for reisomerization of chromophore in adult bovine retina (Bernstein et al., 1987), but it is not clear whether this is also true for other species. Separate studies in our laboratory have shown that cultured neural retina cells can produce retinaldehyde isomers from retinol and retinyl acetate present in their culture medium (Stenkamp et al., 1993; Stenkamp and Adler, 1994). However, we have not been able to demonstrate the presence of l'l-cis retinaldehyde among these isomers, perhaps due to the limits of sensitivity of the HPLC method used. Thus, the existence of light-sensitive photopigment in the cultures is likely, but has not yet been conclusively demonstrated. It is worth mentioning that cultured cells that clearly lack photoreceptor-type visual pigments have been shown to be sensitive to light in vitro, through still undetermined mechanisms (Giebultowicz et al., 1989; Albrecht-Buehler, 1991).

Photoreceptors as a regulable source of melatonin in vitro. The photoreceptor cell type is a likely source of melatonin in vivo (reviewed by Dubocovich, 1988; Cahill and Besharse, 1991). The chicken retina has been shown to contain melatonin-synthesizing activities (Iuvone, 1990; Thomas and Iuvone, 1991) that can be regulated by light and cyclic nucleotides. The mRNA for hydroxyindole- $O$-methyltransferase, the terminal enzyme of the melatonin biosynthetic pathway, has been localized to photoreceptors in chicken retina (Wiechmann and Craft, 1993). The key regulatory enzyme NAT is already present in chick retinas at E6, and begins to be regulated by light by E20 (Iuvone, 1990). NAT activity is present in low-density chick retina cultures similar to the ones used here, is markedly higher in cultures enriched for photoreceptors, is downregulated by dopamine, with a $D_{2}$-type receptor pharmacology, and is increased by treatments that cause increases in cAMP concentrations (Iuvone et al., 1990). $\mathrm{K}^{+}$-evoked depolarization, a treatment that we have now found to elicit dark-adaptive photomechanical movements in vitro, is likely to act directly on the photoreceptors since it is known to increase cAMP (Iuvone et al., 1991) as well as NAT activity in photoreceptor-enriched cultures (Avendano et al., 1990); the increase in melatonin release that could be presumed to result from these changes could be expected to inhibit any depolarization-induced release of dopamine. While these results are consistent with cultured photoreceptors being a regulable source of melatonin in our experiments, we have not been able to measure reliably possible changes in NAT activity in response to light in our cultures.

Nonphotoreceptor neurons as a regulable source of dopamine. Dopamine synthesis and release has been documented in the retinae of several species (Kramer, 1971; Iuvone et al., 1978). The dopamine synthetic enzyme TH has been localized to subtypes of amacrine cells (Brecha et al., 1984) and/or to interplexiform cells (Savy et al., 1989). In developing chick retina, TH-immunoreactive cells are first seen on E1 1, are initially morphologically undifferentiated (Araki et al., 1982; Kagami et al., 1991), and assume their adult positions and morphology by E20. Evidence for the presence of dopaminergic cells in retinal cultures is compelling, but fragmentary. Positive evidence includes the presence of TH-like immunoreactivity in Western blots, its decrease in cultures treated with 6-OHDA, and the intracellular accumulation of ${ }^{3} \mathrm{H}$-dopamine in an $\mathrm{Na}^{+}$-dependent, nomifensine-sensitive manner. Moreover, autoradiographic evidence suggests further that dopamine uptake is predominantly, if not exclusively, associated with nonphotoreceptor neurons and morphologically undifferentiated, process-free round cells.

Accumulation of dopamine into the cultured cells has been demonstrated not only with ${ }^{3} \mathrm{H}$-dopamine, but also by HPLC analysis of cells incubated in the presence of "cold" dopamine (not shown). The radioactive experiments suggest the presence of an uptake system consisting of a high-affinity, low-capacity component and a low-affinity, high-capacity component, similar to those described in other neurons (Efthimiopoulos et al., 1991). Accumulation of ${ }^{3} \mathrm{H}$-dopamine, on the other hand, was not easily measurable unless the incubations were carried out in $\mathrm{Ca}^{2+}$-free buffers, suggesting the presence of a $\mathrm{Ca}^{2+}$-dependent dopamine release mechanism similar to that present in the retina (Dubocovich, 1983; Buatright et al., 1989). The difference between intracellular radioactivity in the absence versus the presence of $\mathrm{Ca}^{2+}$ ions was therefore likely to reflect differences in $\mathrm{Ca}^{2+}$-dependent release; that difference was increased by light (suggesting increased release), and significantly decreased by melatonin (suggesting decreased release). Although these are only indirect estimates of release (which, as explained in Results, was not examined with more direct methods due to the susceptibility of the cells to repeated washing and the low levels of radioactivity involved in the measurements), our results are consistent with known effects of light and melatonin on dopamine release in vivo (Kramer, 1971; Dubocovich, 1983; Boatright et al., 1989; Nowak et al., 1989). To our knowledge, however, a release mechanism via the dopamine transporter has not been investigated in the retina. This mechanism also appears to be regulated by light and melatonin in a manner similar to that observed with the $\mathrm{Ca}^{2+}$-dependent releasable dopamine pool. It is unclear whether both mechanisms coexist in individual cells or are present in different cell types. The presence of distinct and separate releasable pools is suggested by the inability of the $\mathrm{Ca}^{2+}$-dependent mechanism to compensate for the reduced release when the transporter mechanism is blocked by nomifensine.

While the above-mentioned results are consistent with the presence of cells with dopaminergic features, we were frustrated in our attempts to demonstrate the presence of TH-immunopositive cells in the cultures by immunocytochemistry; it is uncertain whether this is due to low antigen concentration in individual cells, and/or to technical problems. Reliable measurements of cellular dopamine or TH activity in the cultures were similarly difficult.

Intercellular communication regulates the response to light in vitro. Pharmacological evidence shows that perturbing the dopaminergic systems in vitro disrupts photomechanical responses to light/dark cycles, suggesting an important role for paracrine 
communication in the regulation and/or establishment of these responses. To our knowledge, in vitro paracrine neuromodulatory systems of this nature have not been reported, although trophic interactions between two cell types in culture have been described (see Watanabe and Raff, 1992), indicating that communication "across the dish" in the absence of visible cell contacts is possible.

$\Lambda$ currently active area of research is the investigation of the respective contributions of external cues and internal modulators in the regulation of rhythmic behaviors such as photomechanical movements (cf. Cahill and Besharse, 1993; Pierce et al., 1993). In the studies described here there is no apparent circadian regulation (but see above), and neuromodulators appear to be secondary to light as regulatory mechanisms. However, since disruption of at least one of these neuromodulatory systems leads to an absence of observed photomechanical responses, we can conclude that in this system, dopaminergic input may be necessary for the regulation and/or establishment of photomechanical responses.

In conclusion, these findings are consistent with the establishment of paracrine communication among cultured cells that are isolated from the retina prior to differentiation. The expression of complex activities such as photomechanical movement and neuromodulator uptake and release, which may be regulated in a coordinated manner, suggests that the differentiation programs for neural retina cells can be expressed in the absence of RPE and glia, in the absence of intraretinal signals, and in the absence of significant cell-cell contact. These differentiation "master programs," once set into action by undetermined mechanisms, may therefore proceed as cell-autonomous programs, with only the nccessity for "permissive" cucs such as dopamine or light for $\mathrm{L}+$ photomechanical elongation.

\section{References}

Adler R (1983) Taurine uptake by chick embryo retinal neurons and glial cells in purified culture. J Neurosci Res 10:369-379.

Adler R (1986) Developmental predetermination of the structural and molecular polarization of photoreceptor cells. Dev Biol 117:520-527.

Adler R (1990) Preparation, enrichment and growth of purified cultures of neurons and photoreceptors from chick embryos and from normal and mutant mice. In: Methods in neuroscience, Vol II (Conn PM, ed), pp 134-150. Orlando: Academic.

Adler R (1993) Plasticity and differentiation of retinal precursor cells. Int Rev Cytol 146:145-190.

Adler R, Hatlee M (1989) Plasticity and differentiation of embryonic retinal cells after terminal mitosis. Science 243:391-393.

Albrecht-Buehler G (1991) Rudimentary form of cellular vision. J Cell Biol 114:493-502.

Araki M, Maeda T, Kimura H (1982) Dopaminergic cell differentiation in the developing chick retina. Brain Kes Bull 10:97-102.

Avendano G, Butler BJ, Iuvone PM (1990) $\mathrm{K}^{+}$-evoked depolarization induces serotonin $N$-acetyltransferase activity in photoreceptor-enriched retinal cell cultures-involvement of calcium influx through L-type channels. Neurochem Int 17:117-126.

Bernstein PS, Law WC, Rando RR (1987) Isomerization of all-trans retinoids to 11 -cis retinoids in vitro. Proc Natl Acad Sci USA 84: $1849-1853$.

Besharse JC, Dunis DA (1983) Methoxyindoles and photoreceptor metabolism: activation of rod shedding. Science 219:1341-1343.

Besharse JC, Dunis DA, Iuvone PM (1984) Regulation and possible role of serotonin $N$-acetyltransferase in the retina. Fed Proc 43:27042708.

Besharse JC, Iuvone PM, Pierce ME (1988) Regulation of rhythmic photoreceptor metabolism: a role for post-receptoral neurons. Prog Ret Res 7:21-61.

Boatright JH, Hoel MJ, Iuvone PM (1989) Stimulation of endogenous dopamine release and metabolism in amphibian retina by light and $\mathrm{K}^{+}$-evoked depolarization. Brain Res 482:164-168.
Bok D (1985) Retinal photoreceptor-pigment epithelium interactions. Invest Ophthalmol Vis Sci 26:1660-1694.

Bowes C, Van-Veen T, Farber DB (1988) Opsin, G-protein and 48$\mathrm{kDa}$ protein in normal and rd mouse retinas: developmental expression of mRNAS and proteins in light/dark cycling of mRNAs. Exp Eye Res 47:369-390.

Braisted JE, Raymond PA (1992) Regeneration of dopaminergic neurons in goldfish retina. Development 114:913-919.

Brann MR, Jelsena CL (1985) Dopamine receptors on photoreceptor membrane couple to a GTP-binding protein which is sensitive to both pertussis and choleratoxin. Biochem Biophys Res Commun 133: 222-227.

Brecha NC, Oyster CW, Takahashi JS (1984) Identification and characterization of tyrosine hydroxylase immunoreactive amacrine cells. Invest Ophthalmol Vis Sci 25:66-70.

Burnside B, Dearry A (1986) Cell motility in the retina. In: The retina: a model for cell biology studies (Adler R, Farber D, eds), pp 152206. Orlando: Academic.

Burnside B, Garcia DM (1992) Inhibition of cAMP-induced pigment aggregation in green sunfish RPE by an organic anion transporter inhibitor probenecid. Invest Ophthalmol Vis Sci 33:1088.

Cahill GM, Besharse JC (1991) Resetting the circadian clock in cultured Xenopus eyecups-regulation of retinal melatonin rhythms by light and D2 dopamine receptors. J Neurosci 11:2959-2971.

Cahill GM, Besharse JC (1993) Circadian clock functions localized to Xenopus retinal photoreceptors. Neuron 10:573-577.

Cohen AI, Todd RD, Harmon S, Omalley KL (1992) Photoreceptors of mouse retinas possess D4 receptors coupled to adenylate cyclase. Proc Natl Acad Sci USA 89:12093-12097.

Dearry A, Burnside B (1986) Dopaminergic regulation of cone retinomotor movement in isolated teleost retinas: I. Induction of cone contraction is mediated by D2 receptors. J Neurochem 46:1006-1021.

Dearry A, Burnside B (1988) Dopamine induces light-adaptive retinomotor movements in teleost photoreceptors and pigment epithelium. In: Dopaminergic mechanisms in vision (I Bodis-Wollner, ed), pp 109-135. New York: Liss.

Dearry A, Edelman JL, Miller S, Burnside B (1990) Dopamine induces light-adaptive retinomotor movements in bullfrog cones via D2 receptors and in retinal pigment epithelium via D1 receptors. J Neurochem 54:1367-1378.

Dowling JE (1978) The interplexiform cell system. I. Synapses of the dopaminergic neurons of the goldfish retina. Proc $\mathbf{R}$ Soc Lond [Biol] 201:7-26.

Dowling JE, Ehinger B (1986) Dopamine: a retinal neuromodulator. Trends Neurosci 9:236-266.

Dubocovich ML (1983) Melatonin is a potent modulator of dopamine release in the retina. Nature 306:782-784.

Dubocovich ML (1988) Rolc of melatonin in retina. Prog Ret Res 6:129-151.

Dubocovich ML, Takahasi JS (1987) Use of 2-[125I]-iodomelatonin to characterize melatonin binding sites in chicken retina. Proc Natl Acad Sci USA 84:3916-3920.

Efthimiopoulos S, Giompres P, Valcana T (1991) Kinetics of dopamine and noradrenaline transport in synaptosomes from cerebellum, striatum and frontal cortex of normal and reeler mice. $J$ Neurosci Res 29:510-519.

Giebultowicz JM, Riemann JG, Raina AK, Ridgway RL (1989) Circadian system controlling release of sperm in the insect testis. Science 245:1098-1100.

Hubbard R, Wald G (1952) The action of light on rhodopsin. J Gen Physiol 36:269-315.

Iuvone PM (1984) Regulation of retinal dopamine biosynthesis and tyrosine hydroxylase activity by light. Fed Proc 43:2709-2713.

Iuvone PM (1986) Evidence for a D2 dopamine receptor in frog retina that decreases cyclic AMP accumulation and serotonin $N$-acetyltransferase activity. Life Sci 38:331-342.

Iuvone PM (1990) Development of melatonin synthesis in chicken retina-regulation of serotonin $N$-acetyltransferase activity by light, circadian oscillators, and cyclic AMP. J Neurochem 54:1562-1568.

Iuvone PM, Galli CL, Garrison-Gurd CK, Neff NH (1978) Light activates tyrosine hydroxylase and increases dopamine synthesis. Science 202:901-902.

Iuvone PM, Avendano G, Butler BJ, Adler R (1990) Cyclic AMPdependent induction of serotonin $\mathrm{N}$-acetyltransferase activity in pho- 
toreceptor-enriched chick retinal cell cultures-characterization and inhibition by dopamine. J Neurochem 55:673-682.

Iuvone PM, Gan J, Avendano J (1991) $\mathrm{K}^{+}$-evoked depolarization stimulates cyclic AMP accumulation in photoreceptor-enriched retinal cell cultures: role of calcium influx through dihydropyridinesensitive calcium channels. J Neurochem 57:615-621.

Jacocks JM III, Cox BM (1992) Serotonin-stimulated release of 3Hdopamine via reversal of the dopamine transporter in rat striatum and nucleus accumbens: a comparison with release elicited by potassium, $N$-methyl-D-aspartic acid, glutamic acid and D-amphetamine. J Pharmacol Exp Ther 262:356-364.

Johnsson G, Malnfors T, Sachs C (1975) 6-Hydroxydopamine as a denervation tool in catecholamine research. Amsterdam: North-Holland.

Kagami H, Sakai H, Uryu K, Kaneda T, Sakanaka M (1991) Development of tyrosine hydroxylase-like immunoreactive structures in the chick retina-three-dimensional analysis. J Comp Neurol 308: 356-370.

Korenbrot JI, Fernald RD (1989) Circadian rhythm and light regulate opsin mRNA in rod photoreceptors. Nature 337:454-457.

Kramer SG (1971) Dopamine: a retinal neurotransmitter. I. Retinal uptake, storage, and light-stimulated release of ${ }^{3} \mathrm{H}$-dopamine in vivo. Invest Ophthalmol Vis Sci 10:438-452.

Kunz YW (1990) Ontogeny of retinal pigment epithelium-photoreceptor complex and development of rhythmic metabolism under ambient light conditions. Prog Ret Res 9:135-196.

Laemmli UK (1970) Cleavage of structural proteins during the assembly of the head of bacteriophage T4. Nature 227:680-685.

Levitt M, Spector S, Sjcerdsna A, Udefriend S (1965) Elucidation of the rate-limiting step in norepinephrine biosynthesis in the perfused guinea pig heart. J Pharmacol Exp Ther 148:1-8.

Lonart G, Zigmond MJ (1990) High glutamatc concentrations croke $\mathrm{Ca}^{++}$-independent dopamine release from striatal slides: a possible role of reverse dopamine transport. J Pharmacol Exp Ther 256:11321138.

Madreperla SA, Adler R (1989) Opposing microtubule- and actindependent forces in the development and maintenance of structural polarity in retinal photoreceptors. Dev Biol 131:149-160.

Madreperla SA, Edidin M, Adler R (1989) $\mathrm{Na}^{+}, \mathrm{K}^{+}$-adenosine triphosphatase polarity in retinal photoreceptors: a role for cytoskeletal attachments. J Cell Biol 109:1483-1493.

Nowak JZ, Zurawska E, Zawilska J (1989) Melatonin and its generating system in vertebrate retina: circadian rhythm, effect of environmental lighting and interaction with dopamine. Neurochem Int $14: 397-406$.
Oka X, Xojina K, Nagotsu T (1983) Characterization of tyrosine hydroxylase from bovine adrenal medulla. Biochem Int 7:387-393.

Paes de Carvalho R, Braas KM, Snyder SH, Adler R (1990) Analysis of adenosinc immunorcactivity, uptake, and release in purified cultures of developing chick embryo retinal neurons and photoreceptors. J Neurochem 55:1603-1611.

Pessin, Adler R (1985) Coexistence of high affinity uptake mechanisms for putative neurotransmitter molecules in chick embryo retinal neurons in purified culture. $\mathrm{J}$ Neurosci Res 14:317-328.

Pierce ME, Besharse JC (1985) Circadian regulation of retinomotor movements. I. Interaction of melatonin and dopamine in the control of cone length. J Gen Physiol 86:671-689.

Pierce ME, Sheshberadaran H, Zhang Z, Fox LE, Applebury ML, Takahashi JS (1993) Circadian regulation of iodopsin gene expression in embryonic retinal cell culture. Neuron 10:579-584.

Politi LE, Adler R (1987) Selective destruction of photoreceptor cells by anti-opsin antibodies. Invest Ophthalmol Vis Sci 28:118-125.

Savy C, Yclnik J, Martin-Martinelli E, Karpouzas I, Nguyen-Legros J (1989) Distribution and spatial geometry of dopamine interplexiform cells in the rat retina. I: Developing retina. J Comp Neurol 289:99110.

Stenkamp DL, Adler R (1993) Photoreceptor differentiation of isolated retinal precursor cells includes the capacity for photomechanical responses. Proc Natl Acad Sci USA 90:1982-1986.

Stenkamp DL, Adler R (1994) Cell type- and developmental stagespecific metabolism and storage of retinoids by embryonic chick retina cells in cultures. Exp Eye Res, in press.

Stenkamp DL, Gregory JK, Adler R (1993) Retinoid effects in purified cultures of chick embryo retina neurons and photoreceptors. Invest Ophthalmol Vis Sci 34:2425-2436.

Thomas KB, Iuvone PM (1991) Circadian rhythm of tryptophan hydroxylasc activity in chicken retina. Cell Mol Neurobiol 11:511-527.

Watanabe T, Raff MC (1992) Diffusible rod-promoting signals in the developing rat retina. Development 114:899-906.

Weichmann A, Craft C (1993) Localization of the mRNA encoding the indoleamine synthesizing enzyme, hydroxyindole- $O$-methyltransferase, in chicken pineal gland and retina by in situ hybridization. Neurosci Lett 150:207-211.

Zarbin MA, Wamsley JK, Palacios JM, Kuhar MJ (1986) Autoradiographic localization of high affinity GABA, benzodiazepine, dopaminergic, adrenergic and muscarinic cholinergic receptors in the rat, monkey, and human retina. Brain Res 374:75-92. 